\title{
Análise Temporal de Redes de Coautorias: Um Estudo sobre as In- terações dos Autores na Revista Brasileira de Informática na Edu- cação
}

Temporal analysis of co-authorship networks: A study on the interactions of Authors in the Brazilian Journal of Computing in Education

Viviane Soares Rodrigues Silva Universidade Federal do Rio de Janeiro vivianerodrig@ppgi.ufrj.br
Fábio Ferrentini Sampaio

Universidade Federal do Rio de Janeiro

ffs@nce.ufrj.br
Jonice Oliveira

Universidade Federal do Rio de

Janeiro

jonice@dcc.ufrj.br

Resumo Este trabalho investiga a existência de padrões de relacionamento em uma comunidade científica e suas tendências ao longo do tempo com o objetivo de identificar se existem e quais são os autores, $e$ as organizações as quais pertencem, que se destacam na produção de artigos em coautoria. Acredita-se que este estudo possibilite prever e sugerir novas conexões entre os autores que produzem artigos para esta comunidade através do fomento à formação de parcerias e a consequente difusão de conhecimento. As redes foram formadas a partir dos autores de artigos científicos publicados na Revista Brasileira de Informática na Educação (RBIE) no período 1997 - 2013. Como principais resultados, concluiu-se que a rede RBIE é composta por pequenas comunidades coesas e desconectadas entre si; que existem autores que se destacam na construção de laços de coautoria, no entanto, ao longo do tempo, as novas conexões não se concentram nestes autores.

Palavras-Chave: Coautoria, Redes Sociais, Evolução Temporal.

\begin{abstract}
This paper investigates the existence of patterns of relationship in a scientific community and its trends over time in order to identify whether there are authors (and their organizations), which stand out in the production of co-authored articles. It is believed that this study enables predict and suggest new connections between authors who produce articles for this community by encouraging the formation of partnerships and the consequent diffusion of knowledge. The networks were formed from the authors of scientific articles published in the Revista Brasileira de Informática na Educação (RBIE) in the period 1997-2013. As main results, it was concluded that the RBIE network consists of small cohesive communities and disconnected from each other; that there are authors who stand in construction of coauthoring bonds, although, over time, new connections do not concentrate in these authors.
\end{abstract}

Keywords: Social Networks, Coauthorship Networks, Temporal Evolution 


\section{1 - Introdução}

As publicações acadêmicas e de pesquisa da comunidade Brasileira de Informática na Educação, representada pela Comunidade Especial de Informática na Educação (CEIE), acontecem basicamente através de três veículos: o Simpósio Brasileiro de Informática na Educação $\left(\mathrm{SBIE}^{1}\right)$, o WorkShop de Informática na Escola (WIE) e a Revista Brasileira de Informática na Educação (RBIE) [1].

Em particular, o amadurecimento e início da RBIE aconteceram durante os SBIEs ocorridos entre os anos 1995 e 1997. O primeiro número da Revista foi lançado em setembro de 1997, contando com os coordenadores das primeiras edições dos SBIEs como núcleo do Comitê Editorial. De fato, a criação da Revista veio trazer incentivo à participação da comunidade de pesquisadores no processo de informatização das escolas. Um panorama desta contribuição nos dez primeiros anos de sua atuação pode ser visto com detalhes em [2].

Os anos que se seguiram expõem os resultados do prosseguimento dos trabalhos na direção do cumprimento da meta principal da Revista: divulgar trabalhos acadêmicos e científicos da área de Informática na Educação. Desde seu primeiro número até a data de escrita deste trabalho somam 43 edições (até o volume 22, número 3 do ano de 2014), com a publicação de 312 artigos, contando com 1479 usuários e 1189 leitores cadastrados (RBIE). Há três edições por ano e, desde 2010, a Revista tornou-se eletrônica, não sendo mais impressa em papel. O acesso ao seu conteúdo é livre pelo site da RBIE.

No entanto, voltando aos desafios levantados em [2], após dez anos de existência e atuação da RBIE ficaram algumas questões, postas como desafios para os dez anos seguintes (em meio aos quais nos encontramos hoje). Dentre estes desafios está o encurtamento das distâncias entre os núcleos de pesquisa e a sala de aula, ou seja, garantir que os resultados exitosos de pesquisas oriundas dos meios universitários tenham nas salas de aula de nossas escolas, nos níveis fundamental e médio, o verdadeiro palco para sua atuação. Para isso, foi sugerido que a própria Revista proporcionasse uma espécie de rede nacional composta por redes regionais de relacionamentos no intuito de aproximar pesquisadores e professores, facilitando as trocas de processos e produtos acadêmicos. Além disso, esta rede de relacionamentos estimularia o compartilhar de experiências, a fim de recomendar aquilo

1 A partir do ano de 2012 o evento tornou-se conhecido como CBIE - Congresso Brasileiro de Informática na Educação, tendo o SBIE e o WIE como eventos integrantes. que funciona, influenciando uns aos outros num processo de colaboração mútua.

Após estes quase 18 anos, têm-se acumulado um acervo não somente de artigos e o conhecimento científico que trazem, mas também uma rica fonte de estudo composta pelos seus respectivos autores que, através da formação de parcerias de coautoria para a realização dos trabalhos publicados, participaram e participam da construção de um emaranhado de relações sociais.

Acredita-se, então, que parte de uma resposta ao desafio mencionado esteja nestas relações pessoais estabelecidas ao longo dos anos de publicações da RBIE, ou seja, na rede social composta pelos autores que publicaram na Revista.

Segundo [3], pelo fato de possuir um caráter invariante e possível de ser verificável, a coautoria pode ser utilizada para avaliar a colaboração científica, e os estudos relativos à Análise de Redes Sociais são uma importante ferramenta para mapear a colaboração entre autores de uma mesma comunidade científica, podendo auxiliar no planejamento de ações estratégicas para que, de maneira otimizada, professores, pesquisadores e alunos sejam estimulados a influenciar uns aos outros, potencializando qualitativa e quantitativamente as produções científicas brasileiras na área de Informática na Educação.

O estudo das redes sociais vem despertando o interesse de pesquisadores de diferentes áreas de pesquisa desde o início do século XX. O trabalho que marca a fundação destes estudos data de 1930 com o psiquiatra Jacob Moreno que estimulou as observações das dinâmicas das interações sociais entre grupos de pessoas e com o lançamento do livro "Who Shall Survive" em 1934 [4]. Desta forma, instituiu-se um novo campo de estudos chamado sociometria, conhecido posteriormente como Análise de Redes Sociais [5].

Ainda de acordo com [5], redes sociais são redes para as quais os vértices (ou atores para os sociólogos) podem ser definidos como pessoas ou grupo de pessoas, e as arestas representam alguma forma de interação social entre eles. É importante ressaltar que o tipo de interação que definirá as arestas dependerá do tipo de questão que se deseja investigar numa dada rede social.

Morel [6], médico epidemiologista, foi um dos primeiros pesquisadores brasileiros a estudar e monitorar a eficiência dos grupos de pesquisas nacionais, utilizando a área de análise de redes sociais para o planejamento estratégico da pesquisa. A intenção era verificar como os grupos (pesquisadores), que tinham o conhecimento sobre doenças, estavam interagindo entre si e com os grupos que fabricavam os medicamentos e vacinas.

Diferentes técnicas podem ser usadas a fim de se descobrir a estrutura de uma rede social, baseada na Teoria 
dos Grafos. Há estudos, por exemplo, que avaliam os índices clássicos da Análise de Redes Sociais, métricas que servem, por exemplo, para destacar vértices na rede, analisar como estão agrupados, o nível de importância e de influência entre os outros vértices $[3,7,8,9]$.

As publicações num periódico científico podem traduzir vários tipos de relações sociais (coautoria, citações, vocabulário comum, etc.). Podendo também serem vistas como um conjunto de artigos que representam um conhecimento comum de uma comunidade de cientistas, quem publica, lê e cita os artigos desta mesma comunidade [10].

Nos últimos anos têm-se intensificado os estudos sobre as redes de coautoria a fim de se investigar e descobrir conhecimento relacionado ao comportamento social entre pesquisadores e grupos acadêmicos [11]. De modo mais específico, algumas verificações são bastante relevantes, como por exemplo, para cada ano de publicação do periódico, levantar a proporção de autores que escrevem juntos [8], calcular o número médio de pessoas com as quais um dado autor escreveu artigos em coautoria [12] e observar o número médio de autores escrevendo juntos um mesmo artigo [3], dentre outras quantificações [7, 11]. Além disso, segundo [9] e [13], é interessante a realização de uma investigação sobre os rumos que tal estrutura de rede está tomando através de uma análise da sua evolução ao longo do tempo.

Através das relações sociais que emergem do processo de coautoria nas publicações dos artigos da única Revista científica da comunidade brasileira de Informática na Educação, este trabalho estuda a evolução temporal de pessoas e seus relacionados que formam a rede social constituída por autores e coautores dos artigos científicos desde 1997, ano de sua fundação, até a última edição do ano de 2013. Espera-se, através dos resultados desta análise, entender como esta comunidade tem se comportado em termos de colaboração na produção de artigos científicos na área de Informática na Educação em épocas diferentes.

Para isso representamos a rede através de uma estrutura em grafo a fim de que, utilizando métricas sobre a sua topologia em diferentes instantes de tempo, obtivéssemos uma visão sobre a evolução desta rede. Em seguida, análises a respeito destes resultados são feitas além de compará-los com outras pesquisas com características semelhantes.

Também, através do uso de métricas que traduzem o grau de influência de um determinado autor e, por isso, sua responsabilidade na disseminação do conhecimento dentro da comunidade que lê e escreve para o periódico estudado, pretende-se trazer à tona aqueles que cumprem este papel na rede formada pelos autores da RBIE e, dessa forma, conscientizá-los e dar estímulo à continuidade de seu trabalho, à formação de novas parcerias e manutenção das que já foram efetivadas.

Sendo assim, este trabalho se estrutura da seguinte maneira: esta seção introdutória, apresentando um breve cenário das publicações fomentadas pela CEIE (Comunidade Especial de Informática na Educação) e em particular o papel da RBIE, trazendo com isso as questões advindas das relações estabelecidas através da publicação de artigos em parceria e a motivação para a escolha do tema tratado. Na seção 2, a metodologia adotada para esta pesquisa, ressaltando o processo do tratamento dos dados, gentilmente disponibilizados pela coordenação da Revista Brasileira de Informática na Educação, cita as métricas escolhidas e aplicadas neste estudo e termina com uma explanação a respeito de como foi feita a geração dos dados e que tipo de análise foi adotado nas seções seguintes. A seção 3 descreve as métricas utilizadas neste estudo, que foram escolhidas pensando-se numa avaliação individual dos vértices das redes construídas, bem como numa avaliação sobre o comportamento da rede como um todo.

A seção 4 traz um levantamento feito sobre trabalhos de Análise de Redes Sociais correlatos às discussões apresentadas, principalmente aqueles que tratam de redes de coautorias. Na seção 5 , as análises dos resultados obtidos são apresentadas e discutidas. Por fim, a seção 6 traz as conclusões para esta pesquisa e sugestões de trabalhos futuros.

\section{Metodologia}

Nesta seção, explicitamos os passos e decisões tomados para a realização deste estudo. Cada subseção descrita a seguir representa uma etapa executada.

\subsection{Tratamento e Estruturação dos Dados}

No contexto da Análise de Redes Sociais, Newman [12] aponta primeiramente a necessidade de se fazer um tratamento cuidadoso sobre o conjunto de dados disponibilizados pelas instituições de pesquisa ou periódicos, conduzindo tal tratamento de acordo com a abordagem escolhida. Os dados relativos às publicações na RBIE foram gentilmente cedidos pela coordenação da Revista em dezembro de 2013, para os fins deste estudo. Consistiam inicialmente de um arquivo .xml, que fora convertido para uma planilha .csv, para melhor manipulação do mesmo. As colunas da tabela gerada continham os seguintes rótulos nesta ordem: palavras-chave, nome dos autores, título do artigo e data de publicação, referentes aos anos de 1997 (desde a primeira edição) até a terceira edição de 2013.

A opção escolhida para construção da rede de relacio- 
namentos, diante dos dados e da maneira como se apresentavam foi, como já dito anteriormente, considerar os autores como os nós da rede e, para cada título que possuía mais de um autor, um novo conjunto de arestas se estabelecia. Na Figura 1(a), os vértices 1, 2, 3, 4, 5 representam os autores e as elipses mostram os grupos que estes autores formaram para, juntos, escreverem um artigo.

Algumas redes, como no caso das redes de coautorias, em um grupo que contenha mais de dois vértices ao mesmo tempo, cada aresta é chamada de hiperaresta e esta rede pode ser chamada de hipergrafo. Esta situação pode ser mostrada através do que se chama, na teoria dos grafos, de um hipergrafo bipartite [5], visto na Figura 1(b).

Para a construção da rede de coautorias relativa às publicações da RBIE, de posse dos registros onde aparecem os nomes dos artigos publicados numa certa edição, pôde-se primeiramente estabelecer uma Rede de Afiliação através da construção de um hipergrafo bipartite. Ou seja, para cada título de artigo, um ou mais autores estão associados. Neste estágio, como mostra a Figura 1(b), o título é o vértice representado pelos círculos abertos identificados pelas letras A, B, C ou D e existe uma aresta entre um título específico e cada autor que participou de sua publicação (vértices representados pelos círculos fechados e identificados por números).

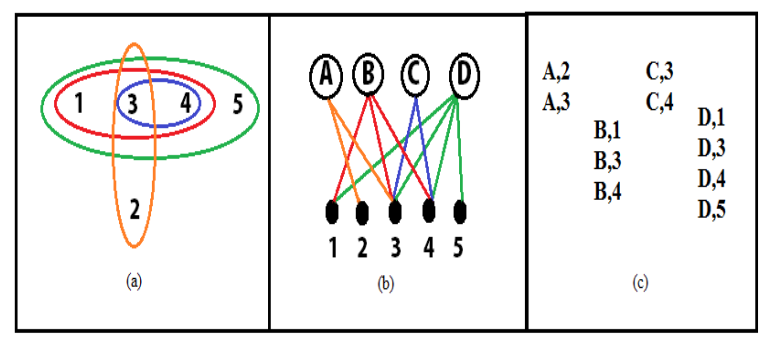

Figura 1: Um hipergrafo e seu correspondente grafo bipartite. As duas redes trazem a mesma informação - cinco vértices em quatro grupos diferentes. (a) hipergrafo no qual os grupos são representados por hiperarestas, denotadas pelos círculos (eventos - artigos) agrupando os vértices (atores - autores). (b) na representação do hipergrafo bipartite foram introduzidos quatro novos vértices (letras A, B, C, D) representando quatro artigos, com arestas conectando cada autor ao artigo que escreveu. (Figura adaptada de [5]) (c) Representação de como foram dispostas as relações entre cada título encontrado nas publicações da RBIE e seus respectivos autores.

Para a efetivação destas relações, um novo arquivo foi gerado contendo apenas as colunas título e autores associados a cada título, exemplificados pela Figura 1(c).

A partir da rede construída, uma próxima etapa no tratamento dos dados coletados sobre as publicações da RBIE foi necessária. Um algoritmo foi aplicado sobre este novo arquivo a fim de que, através da lista de títulos e as relações entre os respectivos autores, tais autores fossem combinados dois a dois para que assim configurasse uma aresta da relação de coautoria de um artigo.

\subsection{Cálculo das Principais Métricas}

De posse deste último arquivo, com os dados relativos a cada ano, partiu-se para a aplicação dos cálculos eleitos como necessários e adequados às questões levantadas neste trabalho.

Para uma avaliação sobre a evolução desta rede ao longo dos anos, seguindo os passos de [12,13] em janelas de tempo de um ano, todas as informações relevantes foram reunidas cumulativamente desde 1997 até o ano de 2013.

Este estudo levou em consideração as métricas individuais (referentes a cada membro da rede social) e as métricas da rede (referentes a rede inteira). A descrição das métricas, bem como a justificativa de seu uso, estão descritas na seção 3. Para o cálculo de tais métricas utilizamos a ferramenta Gephi [21], um software open source útil para a visualização e cálculo das métricas selecionadas. O algoritmo empregado pela ferramenta para o cálculo das centralidades encontra-se descrito em [18].

As métricas foram aplicadas em dois cenários. No primeiro, foram calculadas para o estado atual da rede, ano a ano. Tal análise foi chamada de Análise Estática e está descrita na seção 5.1. Em seguida, as métricas foram calculadas sobre redes construídas através do acúmulo dos dados a cada ano de publicações da Revista. Esta análise foi chamada de Dinâmica e está descrita na seção 5.2. Enquanto a análise estática permite a visão individual de cada período de tempo, auxiliando na percepção e alterações da rede a cada ano, a análise dinâmica permite uma análise sobre os ganhos (e perdas) totais da rede social acadêmica ao longo dos anos estudados.

\subsection{Geração dos Resultados}

Após a geração dos resultados, eles foram analisados e criticados qualitativamente por um especialista da área, interpretando-os à luz dos acontecimentos históricos ocorridos. São apresentados e discutidos na seção 5.

\subsection{Comparação com Trabalhos Correlatos}

Alguns trabalhos relacionados ao tema foram encontrados (descritos na seção 4).

Para que o leitor tenha um entendimento geral, a seguir (seção 3) definimos os conceitos, técnicas e soluções utilizadas na metodologia. 


\section{Métricas Utilizadas}

Considerando, portanto, que o estudo de redes de coautoria trata da análise de uma rede que evolui ao longo do tempo, este trabalho utiliza métricas sobre o conjunto de dados relativo ao período iniciado com a primeira edição da RBIE em 1997 até a terceira edição de 2013, primeiramente tomado ano a ano de modo isolado, construindo uma rede diferente, relativa a cada ano estudado, para a visualização e uma avaliação estática da rede. Em seguida, faz-se a aplicação das mesmas métricas sobre os dados da Revista tomados em janelas anuais referentes aos 17 anos de publicações. Ou seja, a cada janela de um ano, os respectivos dados foram sendo acrescidos àqueles que já compunham a rede de coautorias, formando uma rede de relações contínuas, mantendo os autores e os laços constituídos ao longo dos anos anteriores.

Nas subseções seguintes, encontra-se um detalhamento sobre as métricas adotadas neste trabalho separando-se aquelas que são referentes aos nós de modo individual daquelas que medem o comportamento da rede como um todo.

\section{1 - Métricas Individuais}

Ao se utilizar a topologia da rede, uma das maneiras de se identificar a importância de um vértice é através do cálculo de centralidade. Para isto, existem variadas medidas conhecidas como centralidades de um vértice numa rede.

Uma destas centralidades é o grau do vértice, o número de arestas conectadas diretamente a ele, conhecido também como grau de centralidade [5]. Segundo [15] é o número de laços que um ator (definição da sociologia para vértice numa rede social) constitui com outros atores a ele adjacentes.

Numa rede de coautorias, o grau de um vértice significa o número de autores diferentes com os quais um determinado autor escreveu um artigo em conjunto. Quando um autor escreve mais de uma vez com a mesma pessoa, este fato é caracterizado atribuindo-se um peso relativo a esta quantidade à aresta que liga tais autores, formando assim um grafo ponderado. No presente trabalho, esta ponderação foi feita, no entanto, para fins didáticos, nas explicações a respeito das métricas utilizadas considerou-se que todas as arestas possuem os mesmos pesos.

Numa rede, seja $\mathbf{m}$ o número de arestas que conectam dois vértices desta rede segundo alguma regra de formação e $\mathbf{n}$ o número total de vértices. Chamando de $\mathbf{k}_{\mathbf{i}}$ o grau do vértice $\mathbf{i}$, como proposto em [5], na equação
(3.1) temos o cálculo do número de arestas de um grafo:

$$
m=\frac{1}{2} \sum_{1}^{n} k_{i}
$$

Em geral, pode-se pensar que uma pessoa, numa rede de conhecidos com muitas conexões internas, possa ser alguém com mais influência, com mais acesso a informação ou com mais prestígio que outros presentes na mesma rede [5]. Numa rede de coautorias, um autor com alto grau significa que escreve seus trabalhos com vários autores diferentes, podendo representar neste tipo de rede alguém que tenha uma liderança na área, promovendo, desta forma, a colaboração e integração na produção científica.

Seja a Figura 2 um exemplo de uma rede de coautorias, onde o número de vértices (autores) é igual a 16 e o número de arestas é igual a 18. Nota-se que os autores $\mathrm{A}, \mathrm{B}$ e $\mathrm{C}$, com respectivos graus 6,5 e 5 , representam cada um cerca de $1 / 3$ do número total de conexões nesta rede, sendo assim autores com alto grau de centralidade nesta rede.

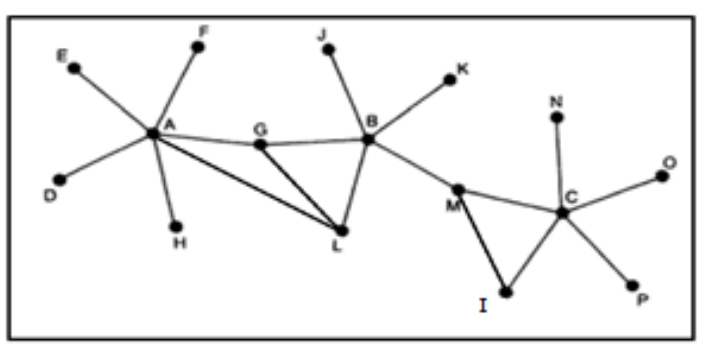

Figura 2 - Exemplo de um grafo.

Na Tabela 1 ilustramos todas as métricas descritas nesta seção levando em consideração o exemplo da Figura 2.

Ainda sobre a centralidade de um vértice (grau do vértice ou grau de centralidade, como vimos anteriormente), esta pode ser observada de modo local, sendo chamada de centralidade local, ou de modo global, conhecida como centralidade global, quando o número de conexões deste vértice é avaliado em relação à rede [16].

A centralidade local de um vértice pode ser absoluta, resultado da soma das arestas diretamente conectadas a ele, ou relativa, ou seja, normalizada pelo número máximo de conexões possíveis. A saber, numa rede com $n$ vértices, existem n-1 possibilidades de conexão para cada vértice [16]. Por exemplo, a Tabela 2 traz estes cálculos para alguns vértices do grafo da Figura 2. 


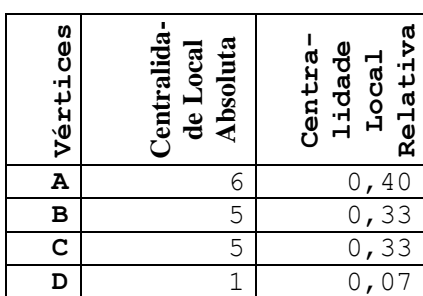

Tabela 1 - Valores da centralidades local relativa e absoluta para o grafo da Figura 2.

A centralidade global de um vértice, também conhecida como closeness ou grau de proximidade, foi definida primeiramente por [17] e é a soma do menor caminho entre este vértice e os demais vértices da rede. Um vértice que tenha a menor soma das menores distâncias está mais perto dos demais. De acordo com a equação utilizada para o cálculo da centralidade global, primeiramente mostrada em [17] e posteriormente normalizada [18] quanto menor a centralidade global, maior será a distância de um membro para com os demais. Isto significa que o trajeto de um dado, informação ou conhecimento para chegar a um destes membros isolados é maior, e consequentemente, pode demorar mais, como também podem chegar deturpados e com ruído. No grafo da Figura 2 vemos que os vértices $\mathrm{N}, \mathrm{O}$ e $\mathrm{P}$, por exemplo, estão visualmente mais isolados dos demais vértices e, de fato, os valores calculados para a centralidade global são os menores para eles, mostrados na Tabela 1.

Numa rede de coautorias, poderíamos pensar que um autor com um número elevado de conexões fosse alguém mais articulado (conseguisse trabalhar e produzir conhecimento com muitas pessoas diferentes) em comparação a um autor com um número de conexões relativamente baixo. No entanto, poderia haver o caso de o primeiro escrever poucos trabalhos com muitas pessoas de cada vez e o segundo, produzir muitos trabalhos variando pouco suas parcerias. Por este, entre outros motivos, esta medida nunca deve ser analisada sozinha para a avaliação da produtividade de um autor.

Neste caso, outra medida de centralidade muito importante e utilizada na Análise de Redes Sociais é a betweenness ou grau de intermediação. Um caminho geodésico, também conhecido como caminho mínimo, entre dois vértices é o menor número de arestas entre estes dois vértices na rede. $\mathrm{O}$ grau de intermediação de um determinado vértice é o número de caminhos mínimos aos quais pertence [5].

O grau de intermediação revela o quanto um vértice está no caminho entre os outros vértices numa rede. Quanto maior for o valor deste grau, significa que este vértice é uma passagem obrigatória entre as menores distâncias entre os vértices de um grafo. A Tabela 1 mostra o autor B com o maior grau de intermediação em relação aos demais vértices. De fato, observando-se a Figura 2, percebe-se que o autor $\mathrm{B}$ está no caminho mínimo entre os vários pares de outros autores. Pitts [19] sugere a ideia de que se este autor $\mathrm{J}$, por exemplo, deseja contatar algum dos autores, C, I, M, N, O ou P precisa utilizar o autor B como uma estação de intermediação.

\begin{tabular}{|c|c|c|c|c|}
\hline 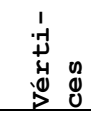 & 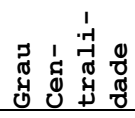 & 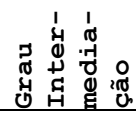 & 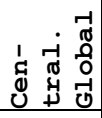 & 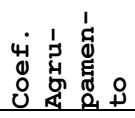 \\
\hline A & 6 & 50 & 0,38 & 0,07 \\
\hline B & 5 & 69 & 0,47 & 0,10 \\
\hline C & 5 & 39 & 0,35 & 0,10 \\
\hline D & 1 & 0 & 0,28 & 0,00 \\
\hline $\mathbf{E}$ & 1 & 0 & 0,28 & 0,00 \\
\hline F & 1 & 0 & 0,28 & 0,00 \\
\hline G & 3 & 23 & 0,43 & 0,67 \\
\hline $\mathrm{H}$ & 1 & 0 & 0,28 & 0,00 \\
\hline I & 2 & 0 & 0,33 & 1,00 \\
\hline $\mathrm{J}$ & 1 & 0 & 0,33 & 0,00 \\
\hline $\mathrm{K}$ & 1 & 0 & 0,33 & 0,00 \\
\hline L & 3 & 23 & 0,43 & 0,67 \\
\hline M & 3 & 50 & 0,42 & 0,33 \\
\hline $\mathbf{N}$ & 1 & 0 & 0,26 & 0,00 \\
\hline 0 & 1 & 0 & 0,26 & 0,00 \\
\hline P & 1 & 0 & 0,26 & 0,00 \\
\hline
\end{tabular}

Tabela 2 - Métricas calculadas para os vértices do grafo da Figura 2.

Um autor com alto valor do grau de intermediação significa que ele conecta grupos diferentes e se for removido, a rede pode ser 'quebrada'. Também pode influenciar na comunicação da rede, atrasando ou perturbando o fluxo de informação, desempenhando um papel crucial na ligação de diferentes comunidades.

Seja $\mathbf{x}_{\mathbf{i}}$ a quantidade de todos os caminhos mínimos entre $\mathbf{s}$ e $\mathbf{t}$ (caso exista mais de um) cujo vértice $\mathbf{i}$ está incluído, então, sendo $\mathbf{n}_{\text {st }}{ }^{i}$ um destes caminhos mínimos entre os vértices $\mathbf{s}$ e $\mathbf{t}, \mathbf{n}_{\mathbf{s t}}{ }^{\mathbf{i}}=\mathbf{1}$, se o vértice $\mathbf{i}$ pertence a este caminho mínimo e $\mathbf{n}_{\mathbf{s t}}{ }^{\mathrm{i}}=\mathbf{0}$ caso contrário [5], como está representado na equação (3.2):

$$
x_{i}=\sum_{s t} n_{s t}^{i}
$$

Seja $\mathbf{g}_{\text {st }}$ o número total de caminhos mínimos entre $\mathbf{s}$ e $\mathbf{t}$, então o grau de intermediação do vértice $\mathbf{i}$ será $\mathbf{X}_{\mathbf{i}}$ calculado através da equação (3.3):

$$
X_{i}=\frac{x_{i}}{g_{s t}}
$$

Esta medida de centralidade difere das demais pois 
não mede quão bem conectado o vértice é, e sim quanto está entre outros. Por exemplo, um autor pode ter centralidade de grau baixa, ou seja, produz com poucos coautores. No entanto, se possuir o grau de intermediação alto significa que está no caminho entre vários autores, ou que sua pesquisa influencia grupos diferentes de autores [5]. Na Figura 2, a influência do autor $M$, observada apenas pelo seu grau de valor 3, número de pessoas diretamente conectadas a ele, não impressiona. Considerando que é o único elo da ligação entre os grupos mostrados, seu grau de intermediação é alto, sua presença ganha a devida importância, pois está numa posição de controle da informação que passa de um grupo ao outro. Esta influência pode significar também o poder de unir assuntos diferentes, trazendo inovação para os grupos que conecta.

Outra métrica, conhecida como coeficiente de agrupamento, pode informar para cada vértice e para a rede como um todo, como uma rede se apresenta em termos de grupos. Voltando ao exemplo representado na Figura 2, tem-se que o autor $\mathrm{J}$ escreveu um artigo com o autor B e o autor B escreveu um artigo com o autor K. Há um caminho de tamanho dois entre os autores $\mathrm{J}$ e $\mathrm{K}$, passando por B. Não significa que, necessariamente, J escreverá com $\mathrm{K}$, mas a probabilidade disto acontecer é maior quando comparada aos demais autores pertencentes à mesma rede. Este tipo de transitividade parcial é comum acontecer nas redes sociais e seu estudo pode ser útil [5]. Ainda no exemplo, se a terceira aresta é formada, $\mathrm{J}$ escreve artigo com $\mathrm{K}$, teremos um loop de tamanho igual a três ou uma a tríade fechada.

Desta análise vem a definição de coeficiente de agrupamento: a probabilidade de dois vizinhos de um vértice serem vizinhos entre si. Isto é, como escrito na equação (3.4), para calcular o coeficiente de agrupamento $\mathbf{C}_{\mathbf{i}}$, são contados todos os pares de vértice que são vizinhos de i e sejam conectados entre si, então, divide-se este valor pelo número total de vizinhos de $\mathbf{i}$, ou $\mathbf{k}_{\mathbf{i}}$, que é o grau de i [5]:

$$
C_{i}=\frac{\text { númerodeparesdevizinhosdeiquesãoconectados }}{\text { númerodeparesdevizinhodei }}
$$

No caso das redes de coautorias, o coeficiente de agrupamento mede o grau com que os nós de um grafo tendem a agrupar-se, mostrando a propensão de alguns autores na formação de grupos coesos em termos de parcerias. Autores com valores elevados para este índice, ou seja, valores próximos a 1, provavelmente são pessoas que possuem mais facilidade para estimular que seus vizinhos formem parcerias entre si. Ou, numa visão matemática, a formação de um triângulo fechado sendo promovida através de triângulos abertos já presentes. Para a análise e visualização deste processo, a construção da rede de coautorias ao longo do tempo deve mostrar como tais parcerias ocorreram e como a rede se encontra atualmente para a efetivação de novos laços. Os vértices (autores) da rede mostrada como exemplo na Figura 2 têm os respectivos coeficientes de agrupamento mostrados na Tabela 1. O vértice I da Figura 2, faz parte de um triângulo fechado, seus únicos dois vizinhos são vizinhos entre si, por isso seu coeficiente de agrupamento é 1. Os vértices $G$ e $L$, com valores altos para esta medida, também fazem parte de triângulos fechados, possuindo ambos apenas dois vizinhos que não possuem conexão entre si.

Em Newman [20], é apresentado outro exemplo de aplicação do coeficiente de agrupamento. O estudo em questão analisa uma rede de colaboração de autores da área de Física a fim de verificar se pares de autores que não tinham colaborado antes, mas que tinham um colaborador mútuo, tinham uma probabilidade maior de colaborarem entre si. Para este caso, em particular, a resposta foi afirmativa, esta probabilidade realmente aumentou. Numa análise posterior, esta probabilidade cresceu quando analisou o início de novos laços de colaboração entre autores com um número maior de colaboradores mútuos.

\section{2 - Métricas da Rede}

Como dito anteriormente, há métricas que se aplicam à realização de uma análise da rede, analisando o grafo por inteiro. É o caso do cálculo do grau médio da rede. Como utilizado em [8, 9, 10 e 12], o grau médio $\mathbf{G}$ da rede representa a média dos graus $\mathbf{k}_{\mathbf{i}}$ (já calculado em 3.1) de seus $\mathbf{n}$ vértices e o cálculo proposto em [5] pode ser visto na equação (3.5):

$$
G=\frac{1}{n} \sum_{i}^{n} k_{i}
$$

Ainda sobre o exemplo da Figura 2, a Tabela 3 mostra os resultados das medidas relevantes para uma análise feita sobre o comportamento da rede como um todo.

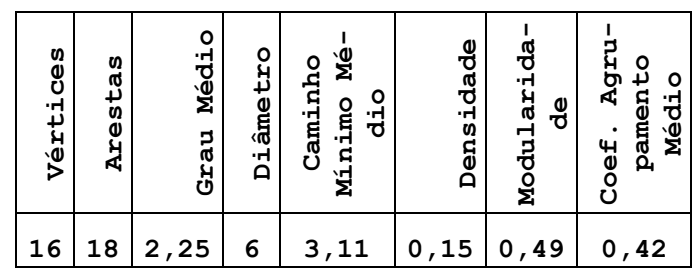

Tabela 3 - Medidas calculadas para o grafo da Figura 2.

Watts e Strogatz [22] propuseram o cálculo do coeficiente de agrupamento médio $\mathbf{C}_{\mathbf{m}}$ para a rede como um todo, através da média do coeficiente de agrupamento local para cada vértice. Ou seja, como mostrado na 
equação (3.6), $\mathrm{C}_{\mathrm{m}}$ é o somatório dos coeficientes de agrupamento de cada vértice do grafo, normalizado pelo número total de vértices.

$$
C_{m}=\frac{1}{n} \sum_{1}^{n} C_{i}
$$

Para alcançar uma maior clareza sobre alguns aspectos da rede estudada deve-se então olhar sua estrutura de outras maneiras. Para isso, outra medida bem útil é aquela que nos fornece a distância média entre um vértice e todos os outros numa mesma rede. A distância entre vértices mede a quantidade de arestas que existem entre eles.

Supondo que $\mathbf{d}_{\mathrm{ij}}$ seja a distância mínima entre o vértice $\mathbf{i}$ e o vértice $\mathbf{j}$, então a distância média $\mathbf{l}$ é calculada como o somatório das distâncias mínimas entre pares de vértices i e j como na equação (3.7):

$$
l_{i}=\frac{1}{n-1} \sum_{i \neq j} d_{i j}
$$

A distância entre duas pessoas que escrevem um artigo juntas é 1 . O valor encontrado para esta medida no caso das redes de coautoria revela quão coesa a rede se apresenta, ou seja, valores relativamente pequenos, quando comparados ao número total de vértices que compõem a rede, mostram que a maioria dos autores não está somente conectada por algum caminho através da rede, mas que este caminho é curto [5].

Já o valor do caminho mínimo médio da rede, é calculado como a média dos caminhos mínimos relativos a cada vértice da rede. Para o exemplo da Figura 2, o caminho mínimo médio é 3.11, mostrando uma distância relativamente curta, comparando com o número total de vértices que é 16 , ou que existem, em média, 3 vértices entre dois vértices quaisquer.

O caminho mínimo médio pode indicar que o alcance, em termos de comunicação dos autores, seja mais rápido quando seu valor é pequeno comparado ao número total de autores de uma rede.

Combinando medidas, imaginando o caso de uma rede com caminho mínimo médio e grau de centralidade médio alto, poderia acreditar-se que é uma rede onde os autores influenciam uns aos outros rapidamente.

Newman em [9,12 e 23] analisou padrões de redes de colaboração baseado em redes de coautorias. Entre outras conclusões, observou que tais redes apresentam o fenômeno small world [22]. Como no experimento de Milgram feito nos Estados Unidos em 1967 [24], onde concluiu que numa rede de conhecidos existem seis graus de separação entre quaisquer duas pessoas, os estudos de Newman [12] mostraram que a distância média entre os pares de cientistas que escrevem artigos juntos nas áreas de Biologia, Física e Matemática, tem o valor próximo a seis, utilizando para este cálculo redes com milhares de cientistas e de artigos que foram publicados em coautoria. Isso reafirma a importância das parcerias de trabalho e das trocas pessoais decorrentes delas como uma ferramenta poderosa no alcance e espalhamento do conhecimento. Um modelo similar foi desenvolvido e analisado por [25].

Uma medida também utilizada na análise temporal feita por [13] e nos trabalhos de $[8,9,12]$ é o diâmetro da rede. Tal medida consiste no maior caminho mínimo (geodésico) entre dois vértices da rede.

Se o diâmetro da rede de coautorias está aumentando ao longo do tempo pode indicar que novos autores estão sendo conectados àqueles que estão nas extremidades desta rede, ou seja, os novos autores estão se conectando com autores que possuem um caminho mínimo grande para com os demais autores desta rede. Isto significa um aumento de autores que provavelmente não se conhecem, não interagiram entre si, e consequentemente, a troca de conhecimento na escrita de artigos passou por mais pessoas até que atingisse aqueles que estão mais distantes na rede. Portanto, quanto maior o diâmetro de uma rede menor a garantia de manutenção da qualidade da informação que trafegou entre os vértices que estão entre aqueles que possuem os maiores caminhos geodésicos entre si.

Outra medida importante é a densidade da rede. A densidade é um parâmetro relativo à configuração geral da rede, e descreve o nível de ligação entre os vértices da rede. Numa rede de coautorias, por exemplo, expressa a relação entre o número de conexões existentes entre os autores e o número máximo total de conexões que poderiam ser constituídas. Newman em [5] define a densidade de uma rede utilizando o grau médio da rede em questão. Primeiramente encontrando o valor de M, o número máximo possível de arestas numa rede de $\mathbf{n}$ vértices, fazendo-se o cálculo de $\left(\begin{array}{l}m \\ 2\end{array}\right)$ - combinação de $\mathbf{n}$ vértices tomados 2 a 2, tem-se a equação (3.8).

$$
M=\left(\begin{array}{l}
n \\
2
\end{array}\right)=\frac{1}{2} \mathrm{n}(n-1)
$$

Se $\mathbf{G}$ é o grau médio já calculado para esta rede com $\mathbf{m}$ arestas, a densidade $\rho$ é obtida fazendo-se como na equação (3.9): 


$$
\rho=\frac{m}{\left(\begin{array}{l}
n \\
2
\end{array}\right)}=\frac{2 \mathrm{~m}}{n(n-1)}=\frac{G}{(n-1)}
$$

Se a densidade de uma rede varia no intervalo $[0,1]$, quanto mais próximo de zero, menos conectada é a rede. A Figura 3 traz um exemplo relacionando diferentes quantidades de nós conectados e a respectiva densidade da rede. A vantagem do uso desta medida está na simplicidade de seu cálculo. No entanto, para redes com extenso número de nós, torna-se custoso realizar tal cálculo.

\begin{tabular}{|c|c|c|c|c|c|c|}
\hline $\begin{array}{l}\text { Número de nós } \\
\text { conectados }\end{array}$ & 4 & 4 & 3 & 3 & 2 & 0 \\
\hline Densidade & 1 & 0.7 & 0.5 & 0.3 & 0.1 & 0 \\
\hline
\end{tabular}

Figura 3.Exemplo da relação do número de nós e a densidade da rede. Adaptada de Scott, J., Social Network Analysis - A Handbook,Sage Publication

Uma rede densa pode se tornar redundante, ou seja, a maioria dos laços já foram formados, os autores já estão bem conectados e realizando trocas de conhecimentos [8 e 26]. A distribuição de uma informação neste tipo de rede é mais rápida. Por outro lado, redes menos densas são um campo aberto para novas relações e novas ideias, sendo um convite a interações com pesquisadores de grupos externos aos já estabelecidos.

Para completar a análise de como uma rede se comporta ao longo do tempo, é importante que seja feita a contabilidade do número de vértices desta rede ao fim de cada período observado e da quantidade de arestas formadas. No caso das redes de coautorias, a partir destes valores pode-se estudar a frequência de adesão de novos autores à rede já existente, o número de autores que escreveram em coautoria, o número de artigos escritos, o número de artigos em coautoria $\mathrm{e}$ as proporções autores/artigo, artigos/autor, artigos em coautoria/artigos e autores em coautoria/autores.

Por fim, outra métrica aplicada à rede é o cálculo da sua modularidade. A modularidade da rede reflete como sua estrutura pode ser decomposta em subpartes, ou seja, quantifica a qualidade da divisão da rede em módulos ou comunidades [13]. Seu cálculo é resultado de um balanço entre a densidade interna a cada módulo e a densidade externa, ou seja, entre os módulos (que é a densidade da rede).

\section{4 - Trabalhos Correlatos}

O cenário de uma rede composta por pesquisadores e a respectiva produção de trabalhos de forma conjunta com outros autores tem sido explorado de maneira distinta ao longo dos últimos anos.

Encontramos alguns trabalhos de Análise de Redes Sociais voltados para a área da Educação como em [11], onde se estuda a dinâmica das relações entre pesquisadores de Programas de Pós Graduação, especificamente em Ciência da Computação, avaliados pela CAPES. Identificaram as relações de coautoria entre os pesquisadores, cujos dados foram coletados via currículos Lattes. Neste trabalho foi desenvolvida e empregada uma heurística para a obtenção de tais relações e, com as redes prontas foi possível concluir que tem havido um aumento nas produções inter e intra Programas de Pós Graduação brasileiros.

Em [27] foi feita uma abordagem, para a Análise da Rede Social estudada, usando técnicas de mineração de dados, a fim de identificar ligações entre os grupos de pessoas com perfis semelhantes. Tais técnicas de agrupamento foram empregadas para identificar grupos de pessoas (por área/ por assunto) de modo que foi possível avaliar como os pesquisadores colaboram no cenário científico brasileiro de Ciência da Computação. Além disso, promoveu-se uma melhor compreensão sobre como a pesquisa flui entre as melhores universidades e centros de pesquisas no Brasil. A compreensão a respeito do cenário científico brasileiro pode ajudar o desenvolvimento da pesquisa em outro cenário ou mesmo em outros tipos de rede social.

Ainda no cenário de um Programa de Pós Graduação, neste caso, em modelagem computacional, em [28] foram estudadas três redes, cada qual construída com base em diferentes tipos de relacionamentos entre os pesquisadores: as redes de pesquisadores atuantes na colaboração de produção bibliográfica, de pesquisadores envolvidos através de projetos de pesquisa, e aqueles relacionados através da participação em comitês de teses de doutorado e dissertações de mestrado. Através de dados a partir de relatórios da CAPES no período de 2001 a 2009, os índices de centralidade indicaram a presença de pesquisadores proeminentes que influenciam e interagem diretamente com outros pesquisadores da rede. Os índices das redes construídas revelaram a presença do fenômeno small world (ou seja, essas redes são favoráveis para aumentar a coordenação entre os pesquisadores) e indicaram um comportamento de distribuição dos graus calculados que mostrou que alguns pesquisadores são mais articulados para realizarem 
conexões que outros (para uma das redes estudadas).

Os estudos em [29] modelaram uma rede social científica multi-relacional onde os pesquisadores podiam ter quatro tipos diferentes de relações uns com os outros. Através de alguns critérios para permitir a modelagem de uma rede social científica fosse o mais próximo possível da realidade e utilizando técnicas de agrupamento, foi possível identificar a estrutura social da rede e avaliar o fluxo de conhecimento na comunidade científica brasileira. Avaliaram também a evolução temporal das redes sociais científicas a fim de que fosse sugerido e/ou previstos novos relacionamentos.

Outros exemplos estão em [3 e 10], onde as relações entre pesquisadores que publicam num mesmo periódico foram estudadas através da análise de uma rede de coautoria formada por palavras pertencentes aos títulos dos respectivos artigos, organizadas em estruturas conhecidas como cliques (grafos ou subgrafos onde os vértices são mutuamente conectados). Segundo [3], um conjunto de palavras que pertencem a um mesmo título formam uma clique e duas cliques se conectam se existir pelo menos uma palavra em comum entre dois títulos.

Em [10] a rede de palavras dos títulos foi analisada ao longo do tempo, e, desta forma foi possível comparar o padrão de conexão entre os vértices de cada rede gerada em épocas diferentes. E em [3], também construiu-se uma rede semântica formada por palavras com significado intrínseco pertencentes aos títulos publicados por seus respectivos coautores.

Existe na literatura análises de métricas clássicas associadas à Teoria dos Grafos, considerando cada autor um vértice da rede e, uma aresta entre dois destes vértices, a escrita de algum trabalho em coautoria, assim como adotado neste trabalho. Dentre estas estão [9, 11, 13, 14 e 23] que aplicam, dentre outras, as métricas clássicas descritas na Seção 2 em diferentes bancos de dados.

Newman [12] realiza suas pesquisas utilizando dados sobre coautorias em periódicos das áreas: de Biomédica, de Física e de Ciência da Computação. Seu objetivo foi o de analisar a estrutura destas redes de coautoria. Para isso, utilizou métricas como: o número de autores das redes, as médias do número de autores por artigo e o número de artigos por autor, calculou o coeficiente de aglomeração para a rede, distância média e diâmetro da rede. Dentre seus resultados ressaltou o número de colaborações para a escrita de um artigo fazendo comparações entre os bancos e respectivas áreas de pesquisa estudadas. Além de concluir que as redes que analisou apresentam o fenômeno small world e são altamente agrupadas.

Já em seu trabalho Newman [9], utilizando bancos de dados das áreas: Biomédica, Física e Matemática, conti- nua buscando padrões de colaboração em redes de coautoria, acrescentando as seguintes questões: como os padrões variam entre as áreas de pesquisa e através do tempo. Concluiu que os padrões de colaboração entre as diferentes áreas apresentam similaridades no sentido de que poucos autores escrevem compondo muitas parcerias e muitos escrevem com poucos parceiros. Além disso, reforçou suas conclusões a respeito da existência das características referentes ao fenômeno small world para este estudo também.

Mendes-da-Silva e outros [8] estudaram os padrões das redes de coautoria formadas por periódicos diferentes da área de Finanças no Brasil. Fizeram uma análise ao longo de 10 anos de publicações utilizando métricas como densidade da rede e seu coeficiente de aglomeração. Avaliaram a centralidade dos vértices através da medida de seu grau de centralidade e grau de intermediação. Assim como [12], inspecionou e confirmou a existência do fenômeno small world. Também concluíram que apenas uma pequena parcela dos autores das Revistas estudadas apresenta produção com regularidade. Outro resultado importante é o de que quanto maior a centralidade dos pesquisadores na rede maior a quantidade de artigos publicados. Outra conclusão importante, em termos de análise do campo de pesquisa estudado, o de Finanças, é de que este tem crescido em número de pesquisadores e trabalhos publicados, levando seus autores a classificarem o campo das Finanças como ainda pouco maduro.

Em [13], foi feito um estudo sobre um único periódico de uma área de conhecimento específica, a Física. Escolheu-se trabalhar métricas como a densidade, o coeficiente de agrupamento médio e a modularidade da rede. Tais métricas foram, num primeiro momento, tomadas de modo estático, utilizando o conjunto de dados tomado como um todo, naquele caso, referentes ao período de janeiro de 1992 a maio de 2003. Verificou-se um diâmetro que foi considerado como um valor alto pelos autores. A modularidade medida combinada com o resultado para o coeficiente de agrupamento para a rede refletiram grafos compostos por várias ilhas conectadas (modularidade alta), compostas por poucas interconexões dentro dos módulos (coeficiente de agrupamento em torno de 0,5 ).

Num segundo momento, os autores consideraram as mesmas métricas tomadas em janelas anuais a fim de se avaliar a evolução de seus resultados, utilizando o conceito TVG (Time-Varying Graph). A análise dos gráficos relativos a tais métricas, observados de modo conjunto, revelou que, durante a primeira metade dos anos estudados, o coeficiente de agrupamento cresceu e o inverso aconteceu com a modularidade da rede, mostrando que as comunidades ou subgrupos existentes se tornaram mais interconectados, mais densos. No 
entanto, a densidade da rede como um todo se manteve estável e com valores baixos (próximos a zero).

$\mathrm{O}$ que foi feito no presente trabalho a respeito da RBIE, assemelha-se a [13], tanto no sentido de se tratar de apenas um periódico analisado quanto em relação à tomada das medidas ao longo do tempo.

Em [10] as relações foram baseadas nos títulos dos artigos publicados em coautoria, ou seja, cada palavra relevante na montagem de um título de um artigo escrito em coautoria é um vértice da rede. As palavras de um mesmo título formam uma clique ${ }^{2}$ e a conexão entre cliques se dá através de palavras em comum entre os títulos. Embora apresente uma abordagem diferente na definição dos elementos que compõem sua rede utiliza-se também do conceito de TVG para analisar indicadores atemporais ao longo do tempo. Avaliam o padrão de conexão de vértices em cada rede do TVG em épocas distintas construídas com os dados relativos a um único periódico e confirmam que a possibilidade de avaliar a evolução da rede ao longo do tempo é ideal para uma percepção sobre as tendências no comportamento dos elementos que interagem numa rede de relacionamentos, no seu caso, a relação entre as palavras de um título que, segundo os autores, representam bem a ideia dos estudos dos pesquisadores.

O Quadro 1 traz um resumo a respeito dos trabalhos correlatos citados, elencando algumas características relevantes para uma comparação com a presente abordagem. Como é possível ver, em termos das métricas utilizadas, a presente pesquisa mais se assemelha aquela encontrada em [8]. No entanto, difere na área acadêmica a qual as Revistas estudadas pertencem. Os demais trabalhos trazem uma abordagem sobre a rede estudada como um todo. Além de [8] apenas [3] utilizam a centralidade de grau dos autores e a explicitam em seus trabalhos.

Esta pesquisa possui um caráter pioneiro no Brasil no sentido de tentar compreender as relações entre pesquisadores e comunidades de pesquisa no campo da Informática na Educação, empregando a metodologia de Análise de Redes Sociais. Está alinhada com o alcance dos desafios propostos em [2], que acredita que a própria RBIE possa configurar uma rede nacional composta por redes regionais de relacionamentos. Os resultados desta pesquisa dirão se já existem estas redes e sub redes, buscando compreender os possíveis rumos dos relacionamentos que às compõem.

${ }^{2}$ Uma clique consiste em um grafo ou subgrafo cujos vértices são mutuamente conectados.

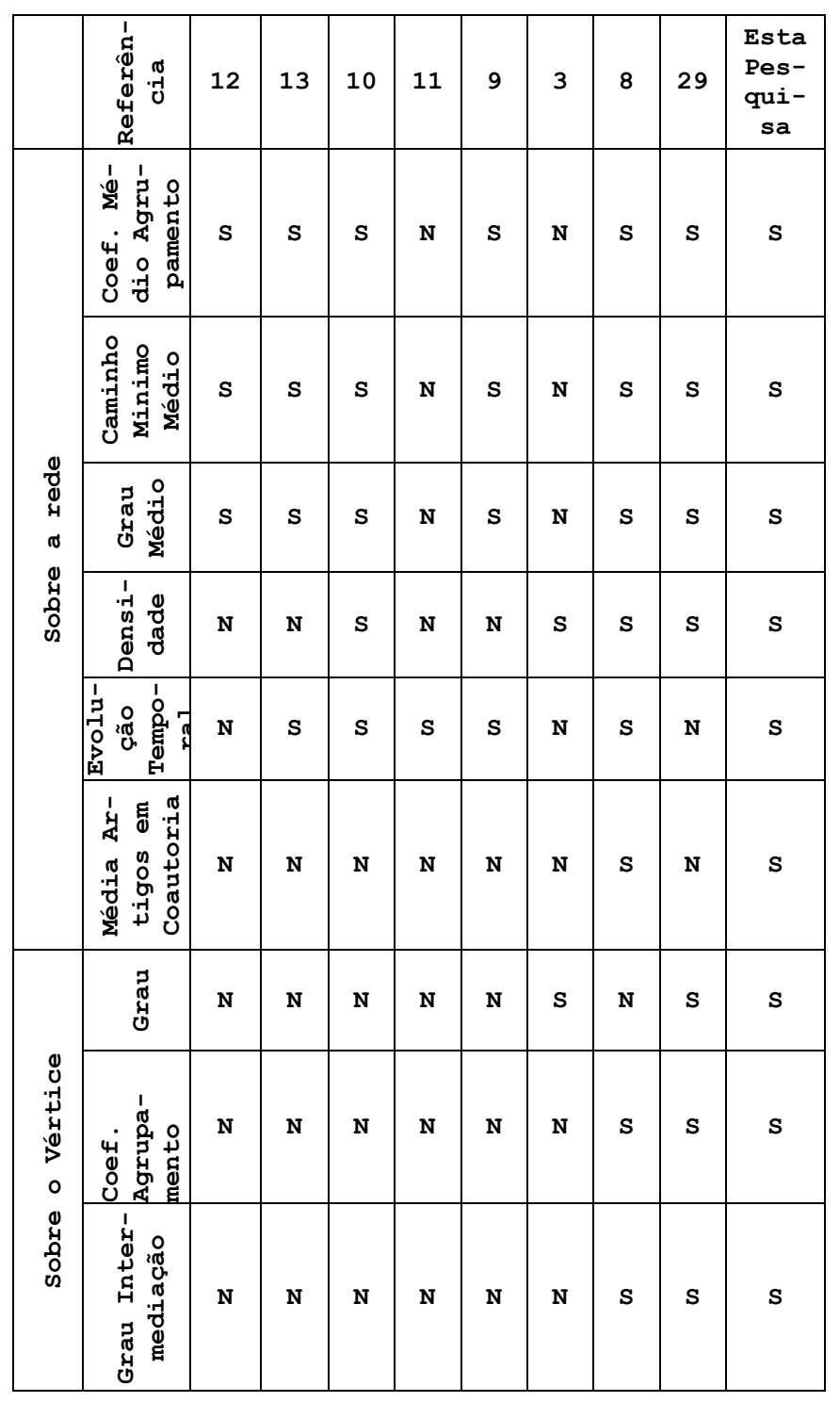

Quadro 1 - Quadro comparativo entre as características presentes nesta pesquisa e trabalhos correlatos. A letra $\mathrm{S}$ indica presença dos resultados das métricas nos trabalhos referenciados e a letra $\mathrm{N}$ indica

Com o auxílio de métricas para análise do comportamento dos autores de modo individual, ficarão evidenciados aqueles que têm desempenhado um papel importante na formação das parcerias e na produção de conhecimento em conjunto.

Enfim, de posse das ferramentas mostradas na Seção 2 , tendo como referencial os trabalhos levantados que lidam com redes de coautorias, a próxima seção traz os quantitativos encontrados no acervo de dados sobre os artigos publicados na RBIE e discussões a respeito dos 
resultados obtidos após a aplicação das métricas utilizadas na Análise de Redes Sociais.

\section{5 - Resultados e Discussões}

Para atender aos objetivos deste trabalho de levantar e compreender a evolução e topologia da rede social composta pelos autores de publicações presentes na RBIE que publicaram em coautoria, primeiramente representou-se a rede utilizando uma estrutura em grafo. Foram contabilizadas as quantidades e proporções retiradas diretamente do arquivo representando a rede de afiliações citada na Seção 2.1.

A Tabela 4 mostra o total de autores e artigos ao longo de 17 anos da existência da Revista, somando 625 e 288 respectivamente. Através da Figura 4 percebe-se que o número de autores na Revista sempre se manteve acima do número de artigos publicados, dando os primeiros indícios de que tais artigos têm sido produzidos de maneira conjunta, por mais que um autor. A partir de 2005, houve uma tendência de aumento no número de autores publicando artigos na Revista. Alguns acontecimentos da época podem estar relacionados a estas variações. No ano de 2005, a Revista passa a ter três volumes anuais, incentivando e abrindo espaço para a publicação de trabalhos em mais um período ao longo do ano. O conteúdo do primeiro volume atenderia a uma demanda específica da CEIE que era a de premiar com a sua publicação na RBIE, os melhores artigos do Simpósio Brasileiro de Informática da Educação (SBIE) e do Workshop de Informática na Escola (WIE). Desde então, os autores premiados são convidados a fazer uma nova submissão dos seus artigos, num formato estendido, e são julgados com o mesmo zelo requerido para qualquer publicação na RBIE.

No mesmo ano, o Comitê de Avaliação da área de Informática da CAPES atribui Qualis Nacional "B" à RBIE. Revelando, por um lado, a qualidade dos trabalhos selecionados e publicados na Revista e por outro, possivelmente servindo de incentivo a um número maior de autores submeterem seus trabalhos à Revista.

O alcance do Qualis Nacional "B" reforça o indício de que a prática de trocas na escrita dos artigos publicados na Revista tem contribuído para a produção de trabalhos de qualidade.

O ano de 2009, porém, é uma exceção, pois revela uma queda no total de autores na rede. Para tentar explicar este acontecimento, consultas foram feitas a especialistas da área, membros da CEIE (Comissão Especial de Informática na Educação), e à ata resultante da reunião desta comissão naquele ano [30]. Verificou-se que houve circulação de uma informação equivocada a respeito do real Qualis atribuído a Revista, divulgado erroneamente como sendo " $\mathrm{C}$ ". Talvez este fato tenha desestimulado a submissão de trabalhos naquele ano.

Ainda através de consulta aos especialistas da área, sabe-se que em 2009 foi divulgado o novo site da Revista (www.brie.or/rbie) e a informação de que a mesma passou a utilizar o sistema SEER(OJS), que entre outras vantagens, facilita a indexação dos artigos pelo Google Scholar, influenciando diretamente no índice $\mathrm{H}^{3}$ da Revista e dos artigos. Fatos estes que podem ter incentivado a submissão de novos trabalhos e entrada de um número maior de autores na rede RBIE.

Desde 2010 tem havido um crescimento no número de autores publicando na Revista. A partir daquele ano, a RBIE passou a ter submissão com fluxo contínuo, não mais existindo datas para envio de artigos. Outro fato relevante é que a partir de 2011, todos os artigos já estavam com DOI (Document Object Information) associado, tornando-os mais visíveis à comunidade.

Voltando à Tabela 4 a coluna que traz a relação do número de artigos por autor representa a produção individual comparada ao número de autores pertencentes à rede. Analisando o intervalo entre os anos 2009 e 2013, vê-se que o número de autores se manteve crescente ao passo que o número de artigos, produzidos por autor, decaiu neste mesmo período. Pode-se então verificar um aumento na prática de escrita em colaboração.

Ainda observando a Tabela 4, na coluna que traz a relação do número de autores por artigo, podem ser vistos os anos onde mais autores estiveram envolvidos em parcerias de coautoria: 2001, 2008 e 2013, chegando a 3,5 autores por artigo no último ano analisado. Talvez o crescimento constante da relação de autores em coautoria por artigo, seguindo a mesma tendência de crescimento do número de autores, explique que uma cultura de formação de coautorias está presente na comunidade de Informática na Educação.

${ }^{3}$ Indice $\mathrm{H}$ é um métrica que vem sendo usada para definir o Qualis de periódicos. 


\begin{tabular}{|c|c|c|c|c|c|c|c|c|c|c|c|}
\hline 号 & 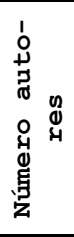 & 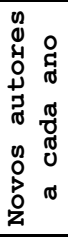 & 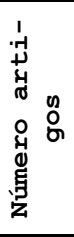 & 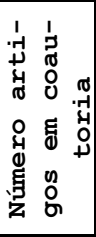 & 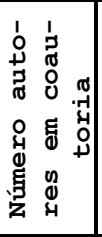 & 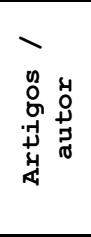 & 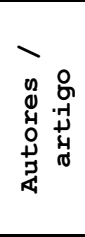 & 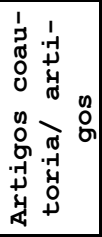 & 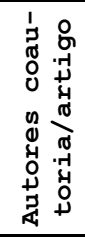 & 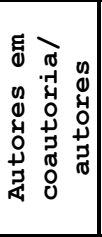 & 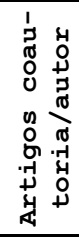 \\
\hline 97 & 27 & 27 & 13 & 6 & 20 & 0,48 & 2,08 & 0,46 & 1,54 & 0,74 & 0,22 \\
\hline 98 & 38 & 36 & 19 & 10 & 29 & 0,50 & 2,00 & 0,53 & 1,53 & 0,76 & 0,26 \\
\hline 99 & 37 & 35 & 19 & 12 & 30 & 0,51 & 1,95 & 0,63 & 1,58 & 0,81 & 0,32 \\
\hline 00 & 25 & 22 & 12 & 9 & 23 & 0,48 & 2,08 & 0,75 & 1,92 & 0,92 & 0,36 \\
\hline 01 & 43 & 35 & 16 & 14 & 41 & 0,37 & 2,69 & 0,88 & 2,56 & 0,95 & 0,33 \\
\hline 02 & 28 & 21 & 13 & 9 & 24 & 0,46 & 2,15 & 0,69 & 1,85 & 0,86 & 0,32 \\
\hline 03 & 28 & 23 & 12 & 10 & 26 & 0,43 & 2,33 & 0,83 & 2,17 & 0,93 & 0,36 \\
\hline 04 & 28 & 26 & 11 & 9 & 26 & 0,39 & 2,55 & 0,82 & 2,36 & 0,93 & 0,32 \\
\hline 05 & 41 & 31 & 15 & 15 & 41 & 0,37 & 2,73 & 1,00 & 2,73 & 1,00 & 0,37 \\
\hline 06 & 43 & 34 & 17 & 16 & 42 & 0,40 & 2,53 & 0,94 & 2,47 & 0,98 & 0,37 \\
\hline 07 & 48 & 43 & 15 & 11 & 44 & 0,31 & 3,20 & 0,73 & 2,93 & 0,92 & 0,23 \\
\hline 08 & 45 & 41 & 16 & 15 & 42 & 0,36 & 2,81 & 0,94 & 2,63 & 0,93 & 0,33 \\
\hline 09 & 39 & 26 & 16 & 15 & 38 & 0,41 & 2,44 & 0,94 & 2,38 & 0,97 & 0,38 \\
\hline 10 & 45 & 34 & 18 & 15 & 40 & 0,40 & 2,50 & 0,83 & 2,22 & 0,89 & 0,33 \\
\hline 11 & 52 & 42 & 19 & 19 & 52 & 0,37 & 2,74 & 1,00 & 2,74 & 1,00 & 0,37 \\
\hline 12 & 81 & 66 & 27 & 24 & 78 & 0,33 & 3,00 & 0,89 & 2,89 & 0,96 & 0,30 \\
\hline 13 & 101 & 83 & 30 & 28 & 96 & 0,30 & 3,37 & 0,93 & 3,20 & 0,95 & 0,28 \\
\hline
\end{tabular}

Tabela 4 -Quantitativo do número de autores, artigos e relações de coautorias.

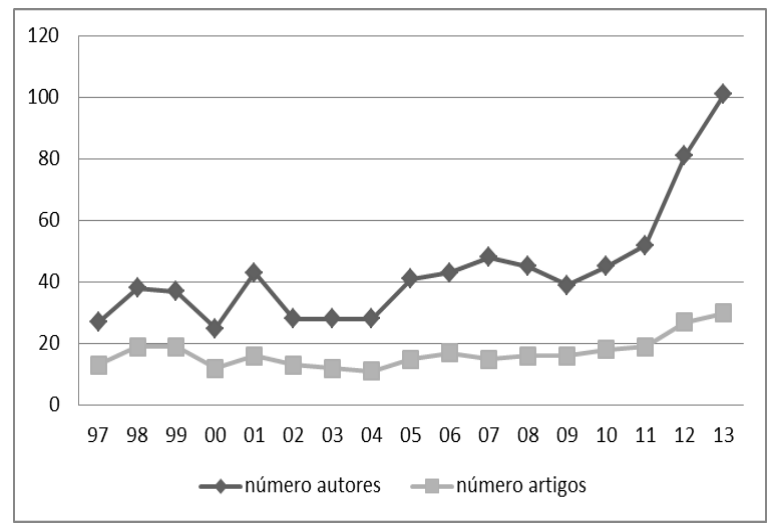

Figura 4 - Número de autores e artigos desde 1997 até 2013.

Até este ponto, apenas com os totais extraídos diretamente dos dados disponibilizados, não é possível analisar as relações de parceria entre autores, realizadas na escrita dos artigos. A construção de uma rede, estabelecendo seus vértices e arestas, é de grande importância para obter-se um melhor entendimento sobre as coautorias da RBIE como um todo. Utilizando as ferramentas que a Análise de Redes Sociais fornece, foram calculados os índices ditos clássicos: número de vértices, número de arestas, grau médio, grau médio ponderado, diâmetro, caminho mínimo médio, densidade, modularidade e coeficiente de agrupamento médio, cujos resultados poderão ser vistos na Tabela 5, da seção 5.1.1.

Para a análise do comportamento dos autores da rede de coautorias as métricas calculadas foram: grau de centralidade, grau de intermediação, centralidade global e coeficiente de agrupamento.

Estes resultados estão organizados para as redes formadas por dados referentes aos anos de publicações da RBIE, tomados um a um, de modo isolado (seção 5.1), representando o que aconteceu em cada ano específico, independente das relações nos anos anteriores.

Na seção seguinte, seção 5.2, observa-se a evolução da rede RBIE, reconstruída a cada ano pelo ingresso de novos autores, realização de novas parcerias e retomada de parcerias já feitas anteriormente. Os dados relativos a cada ano foram acrescentados, de modo cumulativo, aos que representavam os anos anteriores.

\section{1 - Análise Estática}

Como mencionado anteriormente, num primeiro mo- 
mento, as métricas selecionadas, tanto para a análise da rede vista como um todo, como para uma avaliação individual dos vértices, foram tomadas ano a ano, de modo estático, como pode ser visto através das tabelas que se seguem.

\subsection{1 - Medidas relativas à rede}

A Tabela 5 traz os resultados das métricas aplicadas sobre as redes construídas, relativas a cada ano estudado. Tais resultados serão discutidos a seguir.

\begin{tabular}{|c|c|c|c|c|c|c|c|c|}
\hline$\stackrel{\circ}{\stackrel{4}{4}}$ & 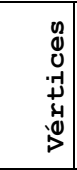 & 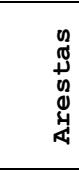 & 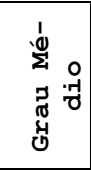 & 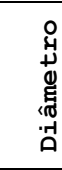 & 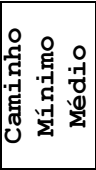 & $\begin{array}{l}0 \\
0 \\
0 \\
7 \\
-7 \\
0 \\
0 \\
0 \\
0 \\
0\end{array}$ & 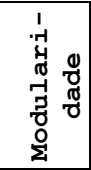 & 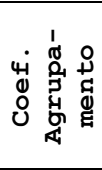 \\
\hline 97 & 20 & 26 & 2,6 & 1 & 1 & 0,137 & 0,77 & 1 \\
\hline 98 & 30 & 33 & 2,2 & 2 & 1,15 & 0,076 & 0,8 & 0,97 \\
\hline 99 & 32 & 38 & 2,37 & 2 & 1,09 &, 07 & 0,79 & 0,94 \\
\hline 00 & 2 & 20 & 1,74 & 1 & 1 & 0,079 & 0,83 & 1 \\
\hline 01 & 41 & 43 & 2,09 & 1 & 1 & 0,052 & 0,9 & 1 \\
\hline 02 & 2 & 25 & 2,08 & 1 & 1 & 0,091 & 0,75 & 1 \\
\hline 03 & 26 & 29 & 2,23 & 2 & 1,19 & 0,089 & 0,8 & 0,93 \\
\hline 04 & 26 & 2 & 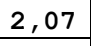 & 1 & 1 & 83 & 0,84 & $\perp$ \\
\hline 05 & 40 & 44 & 2,2 & 1 & 1 & 0,056 & 0,87 & 1 \\
\hline 06 & 41 & 72 & 3,5 & 2 & 1,17 & 0,088 & 0,74 & 0,98 \\
\hline 07 & 44 & 84 & 3,81 & 2 & 1,12 & 0,089 & 0,83 & 0,97 \\
\hline 08 & 45 & 57 & 2,5 & 2 & 2 & 58 & 0,89 & 0,96 \\
\hline 09 & 3 & 3 & 2,1 & 2 & 1,05 & 055 & 0,88 & 0,92 \\
\hline 10 & 43 & 53 & 2,47 & 3 & 1,53 & 0,059 & 0,78 & 0,93 \\
\hline 11 & 51 & 56 & 2,19 & 2 & 1,11 & 0,044 & 0,89 & 0,96 \\
\hline 12 & 74 & 92 & 2,48 & 1 & 1 & 0,034 & 0,93 & 1 \\
\hline 13 & 95 & 160 & 3,37 & 2 & 1 & 0,036 & 0,88 & 0,99 \\
\hline
\end{tabular}

Tabela 5 - Medidas da rede RBIE calculadas ano a ano.

Analisando o número de vértices e de arestas, até o ano de 2005, o número de arestas fica sempre bem próximo ao número de vértices, o que significa que, a maioria dos artigos foi escrita por apenas 2 autores (lembrando que uma aresta representa uma conexão entre duas pessoas). De fato, a partir do ano de 2005, o número de arestas chega a ser quase o dobro do número de vértices, mas há um brusco decréscimo nos anos 2008 e 2009, onde o número de parcerias na escrita de trabalhos publicados que, em 2007 chega a 84, em 2009 fica em 39. Pode-se associar esta queda nas relações de coautoria ao mesmo fato já descrito na introdução desta seção com relação ao Qualis atribuído à Revista. Vê-se que o impacto não ficou apenas no número reduzido de autores escrevendo para a Revista, parece que também produziu um desestímulo à formação de parcerias.
Nos anos subsequentes, de 2010 a 2013 o número de arestas voltou a crescer, atingindo um novo pico em 2013, com 160 parcerias para a escrita de trabalhos.

Pode-se acompanhar que o diâmetro da rede aumentou em 1998, 2003, 2006 e 2010 enquanto o coeficiente de agrupamento e a modularidade se mantiveram quase constantes o tempo todo.

Em comparação, as evoluções da modularidade e do coeficiente de agrupamento médio da rede mostram tendências, em termos de crescimento e decrescimento, semelhantes. A modularidade medida, manteve-se em torno de 0,8 , um valor próximo a 1 , que combinado com os resultados para o coeficiente de agrupamento para a rede, valores entre 0,9 e 1 , refletiram grafos compostos por várias ilhas conectadas (modularidade alta), compostas por alta interconexão (coeficiente de agrupamento alto), revelando que os autores que publicaram na RBIE ao longo dos anos mantiveram a característica de publicarem em grupos interconectados entre si e, geralmente, disjuntos, formando as ilhas mencionadas.

Ainda sobre os anos de 2001, 2005 e 2012, quando se vê um aumento significativo no número de vértices com relação ao ano anterior, o diâmetro da rede se mantém no valor de 1. Este fato levanta o questionamento sobre a possibilidade de grupos isolados terem entrado na rede naqueles anos.

Os valores calculados para a densidade foram baixos, começou em 0,15 no primeiro ano de publicação e decresceu chegando ao índice de 0,036 em 2013, ano onde houve o maior número de autores em coautoria. A disseminação do conhecimento neste tipo de rede fica prejudicada, pois as trocas ficam restritas a grupos pequenos. Por outro lado, como dito anteriormente, redes menos densas são uma oportunidade para novas relações e uma mostra da necessidade de incentivo à realização de novas interações com pesquisadores de grupos diferentes aos quais já faz parte. Desta forma, o decréscimo nos valores da densidade da rede somado a constância nos valores da modularidade e o coeficiente de agrupamento pode significar que os módulos (ou grupos) formados não colaboram entre si, podendo até mesmo configurar grupos que estão competindo entre si.

Analisando o número de vértices em conjunto com o grau médio da rede a cada ano, destacam-se dois momentos. O primeiro, em 2007, quando o grau médio da rede atinge um pico no valor de 3,8 , o número de vértices da rede neste mesmo ano não sofre alteração significativa em relação ao ano anterior, mostrando um ano que se destaca pelas parcerias para a escrita de trabalhos. Por outro lado, o ano de 2009 traz uma queda na participação dos autores através de coautorias, com um valor baixo para o grau médio da rede chegando a 2,1. 
Em continuidade à análise estática da rede, a seção a seguir avalia o papel dos autores à luz das métricas já anteriormente definidas.

\subsection{2 - Medidas relativas aos autores}

Analisando os resultados dos índices atingidos pelos autores para a centralidade de grau, a Tabela 6 mostra os identificadores numéricos dos dez autores que alcançaram os maiores graus a cada ano. Como se pode ver, há um grande revezamento de autores de um ano para outro ocupando destaque em centralidade de grau. Pelo fato, já comentado, de a RBIE ser uma rede formada por grupos isolados, as métricas centralidade global e coeficiente de agrupamento não se mostraram expressivas para a análise individual dos autores. Para as redes construídas com os dados de cada ano de modo isolado, resultaram valores iguais para todos e, portanto, não apontaram a existência de algum autor que tenha se destacado num ano específi- co.

A métrica grau de intermediação destacou os autores em cada ano, no entanto há anos onde para todos os autores o valor calculado foi zero. Chegando a, no máximo, quatro valores diferentes de zero em outros anos, como pode ser visto na Tabela 7.

Assim como para os maiores graus de centralidade, existe também uma alternância entre autores mais influentes quando consideramos o grau de intermediação. Apenas um autor aparece em dois anos diferentes, o autor 101, nos anos 2003 e 2009, os demais aparecem apenas uma vez ao longo dos 17 anos estudados. Isso possivelmente se deve ao fato de que poucos autores publicaram em anos consecutivos e de que não existiu, até aqui, um grupo ou autor dentro da comunidade que sobressaísse frequentemente em termos de número de parcerias formadas.

\begin{tabular}{|c|c|c|c|c|c|c|c|c|c|c|c|c|c|c|c|c|c|c|c|c|c|c|c|c|c|c|c|c|c|c|c|}
\hline \multicolumn{2}{|c|}{1997} & \multicolumn{2}{|c|}{1998} & \multicolumn{2}{|c|}{1999} & \multicolumn{2}{|c|}{2000} & \multicolumn{2}{|c|}{2001} & \multicolumn{2}{|c|}{2002} & \multicolumn{2}{|c|}{2003} & \multicolumn{2}{|c|}{2004} & \multicolumn{2}{|c|}{2005} & 2006 & \multicolumn{2}{|c|}{2007} & \multicolumn{2}{|c|}{2008} & \multicolumn{2}{|c|}{2009} & 2010 & \multicolumn{2}{|c|}{2011} & \multicolumn{2}{|c|}{2012} & \multicolumn{2}{|c|}{2013} \\
\hline \multicolumn{6}{|c|}{ id rau } & id $g$ & $\mathrm{r}$ & 1 & & 1 & ra & & & 18 & rau & id $\mathrm{g}$ & & id $\mathrm{gr}$ & & 1 & & gra & id & gra & id gr & & d gra & id & grau & & grau \\
\hline 12 & 4 & 56 & 5 & 90 & 5 & 102 & 3 & 126 & 3 & 171 & 4 & 187 & 5 & 217 & 3 & 101 & 4 & 152 & 8 & 0 & 347 & 6 & 263 & 3 & 114 & 3. & 12 & & 4 & 556 & 8 \\
\hline 13 & 4 & 50 & 4 & 91 & 5 & 103 & 3 & 127 & 3 & 172 & 4 & 101 & 3 & 218 & 3 & 149 & 4 & 272 & $J$ & & 358 & 4 & 313 & & 410 & 4 & 49 & & 4 & 557 & 8 \\
\hline 14 & 4 & 5 & 4 & 92 & 5 & 104 & 3 & 128 & 3 & 173 & 4 & 100 & 3 & \begin{tabular}{|l|}
219 \\
\end{tabular} & - & 252 & 4 & 273 & 2 & 5 & 346 & 4 & 331 & 3 & 409 & 4 & $\begin{array}{lll}50 & 4 \\
\end{array}$ & & 4 & 558 & 8 \\
\hline 15 & 4 & 52 & 4 & 93 & 5 & 105 & 3 & 129 & 3 & 174 & 4 & 181 & 3 & 220 & 3 & 253 & 4 & 274 & 2 & 6 & 348 & 4 & 80 & 3 & 367 & 4. & $\begin{array}{lll}51 & 4\end{array}$ & & 4 & 559 & 8 \\
\hline 16 & 4 & 53 & 4 & 94 & 5 & 106 & 2 & 135 & 3 & 175 & 4 & 182 & 3 & 221 & 3 & 254 & 4 & 275 & 29 & 7 & 349 & 4 & 385 & 3 & 418 & 4. & \begin{tabular}{l|l}
52 & 4 \\
\end{tabular} & & 4 & 560 & 8 \\
\hline 5 & 3 & 54 & 4 & 95 & 5 & 107 & 2 & 136 & J & 166 & 3 & 183 & 3 & 222 & 3 & 234 & J & 276 & 2 & & 350 & 4 & 386 & 3 & 417 & 4. & 53 & & 4 & 561 & 8 \\
\hline 6 & 3 & 58 & 3 & 33 & 3 & 108 & 2 & 137 & 3 & 167 & 3 & 134 & 3 & 223 & 3 & 235 & 3 & 277 & 2 & & 334 & 3 & 387 & 3 & 421 & 3 & 13 & 508 & 4 & 562 & 8 \\
\hline 7 & 3 & 59 & 3 & 28 & 3 & 113 & 2 & 89 & 3 & 168 & 3 & 188 & 3 & 224 & 3 & 236 & & 278 & 4 & & 335 & 3 & 388 & 3 & 420 & & \begin{tabular}{l|l}
36 & 3
\end{tabular} & 364 & 4 & 420 & 8 \\
\hline 8 & 3 & 60 & 3 & 65 & 2 & 114 & 2 & 150 & 3 & 169 & 3 & 189 & 3 & 202 & 2 & 237 & & 279 & 3 & & 336 & 3 & 312 & 3 & 419 & & \begin{tabular}{l|l}
09 & 3
\end{tabular} & 509 & 4 & $367 \mid$ & 8 \\
\hline 9 & 2 & 35 & 2 & 66 & 2 & 115 & 2 & 151 & 3 & 101 & 2 & 97 & 3 & 36 & 2 & 239 & 3 & 172 & 3 & & 337 & 3 & |474 & 3 & 408 & & \begin{tabular}{l|l}
68 & 3
\end{tabular} & 510 & 4 & 578 & 8 \\
\hline
\end{tabular}

Tabela 6 - Lista dos dez autores com maiores centralidades de grau a cada ano. Estão listados do maior grau para o menor. Os identificadores dos autores que estão sombreados são aqueles que também se destacam por terem algum grau de intermediação nas redes respectivas a cada ano.

\begin{tabular}{|l|c|c|c|c|c|c|c|c|c|c|c|c|c|c|c|c|c|c|c|c|c|c|}
\hline Ano & $\mathbf{9 8}$ & $\mathbf{9 9}$ & $\mathbf{9 9}$ & $\mathbf{0 3}$ & $\mathbf{0 3}$ & $\mathbf{0 3}$ & $\mathbf{0 6}$ & $\mathbf{0 7}$ & $\mathbf{0 7}$ & $\mathbf{0 8}$ & $\mathbf{0 8}$ & $\mathbf{0 8}$ & $\mathbf{0 9}$ & $\mathbf{0 9}$ & $\mathbf{1 0}$ & $\mathbf{1 0}$ & $\mathbf{1 0}$ & $\mathbf{1 0}$ & $\mathbf{1 1}$ & $\mathbf{1 1}$ & $\mathbf{1 3}$ & $\mathbf{1 3}$ \\
\hline $\begin{array}{l}\text { Grau } \\
\text { Inte rme } \\
\text { diação }\end{array}$ & 6 & 2 & 2 & 6.0 & 0.5 & 0.5 & 15 & 9 & 3 & 8.0 & 4.0 & 2.0 & 1.0 & 1.0 & 28 & 9 & 7 & 7 & 7 & 1 & 1 & 1 \\
\hline Autor & 56 & 33 & 28 & 187 & 101 & 100 & 152 & 80 & 301 & 347 & 358 & 367 & 101 & 344 & 114 & 367 & 409 & 410 & 312 & 313 & 536 & 537 \\
\hline
\end{tabular}

Tabela 7 - Graus de intermediação alcançados pelos autores a cada ano. São mostrados todos os autores com grau de intermediação para cada ano. Há anos onde o grau de intermediação foi zero para todos os autores. Os identificadores dos autores que estão sombreados são aqueles que também se destacaram em centralidade de grau no respectivo ano.

Observando a Tabela 6, os autores em destaque (sombreados) são aqueles que também aparecem na Tabela 7 (autores com maiores graus de intermediação). Nem todos os anos da Tabela 6 possuem autores destacados, indicando que não necessariamente aquele que é mais central, medido pelo seu grau, será também intermediário de outras relações. Do contrário, na Tabela 7, somente 3 anos mostram autores ocupando uma posição de intermediação nas relações que, ao mesmo tempo, não pertencem à lista dos maiores graus no respectivo ano (observada na Tabela 6). 


\section{2 - Análise Acumulada}

As análises desta seção baseiam-se nos resultados da aplicação das métricas sobre redes construídas através do acúmulo dos dados a cada ano de publicações da Revista RBIE, desde 1997 a 2013. A análise da rede construída desta forma fornece uma espécie de memória a respeito do que já vem acontecendo ao longo dos anos de publicações na Revista. Seguindo uma abordagem que considera que uma coautoria pode ser vista como um tipo de relação (laços foram feitos) que não se rompe, ou seja, mesmo que estes autores nunca mais tenham trabalhado juntos, estas conexões não são desfeitas. Por outro lado, tais conexões precisam ser evidenciadas e incentivadas de alguma maneira para que permaneçam ativas, ou seja, estas parcerias voltem a acontecer e através delas outras venham a surgir.

Para a análise da rede, serão alvo de discussão o grau médio da rede, o coeficiente de agrupamento médio, o diâmetro, o caminho mínimo médio, a densidade e modularidade.

$\mathrm{Na}$ investigação a respeito dos autores serão consideradas as medidas: centralidade de grau, grau de intermediação, centralidade global e do coeficiente de agrupamento.

\subsection{1 - Medidas relativas à rede}

A Tabela 8 traz os resultados da aplicação das métricas selecionadas. Os valores estão explicitados ano a ano cumulativamente, somando 583 vértices e 874 arestas ao final do ano de 2013.

A Figura 5 traz a comparação entre a evolução do número de arestas, vértices e a densidade da rede. Mostra uma rede em crescimento na participação de novos autores (número de vértices crescente) e na formação de parcerias na escrita de artigos (número de arestas). A partir do ano de 2005, a taxa de crescimento do número de arestas começa a apresentar-se maior que a dos vértices, mostrando que os artigos publicados na Revista são fruto de colaboração entre mais que 2 autores. No entanto, os valores baixos para a densidade revelam uma rede tendendo a ser cada vez mais esparsa. Como dito anteriormente, um campo aberto ao incentivo às trocas entre aqueles que já tiveram trabalhos publicados na RBIE e aqueles que ainda estão desconectados dos demais autores.

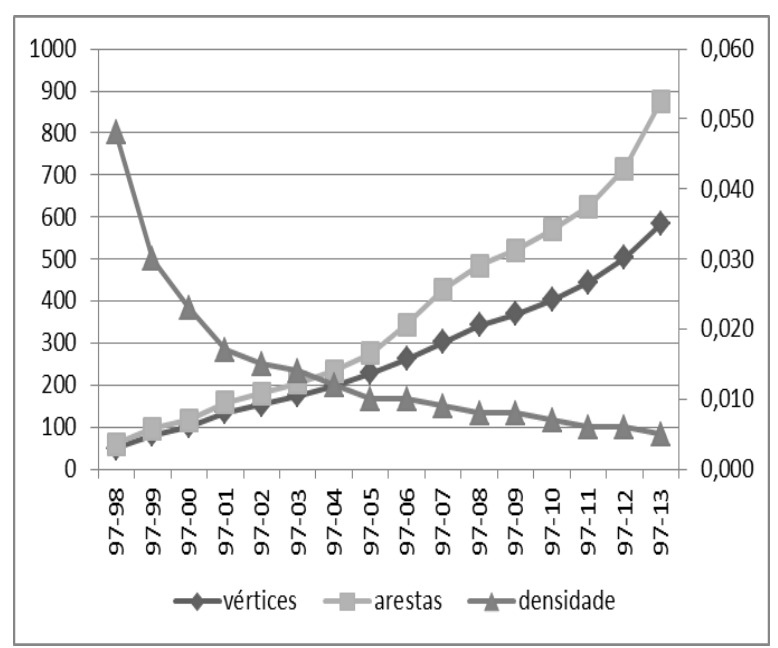

Figura 5 - Evolução do número de vértices e arestas (eixo da esquerda) comparada com a evolução do valor calculado para a densidade.

Com a entrada de novos autores na rede RBIE a cada ano, embora o valor do coeficiente de agrupamento médio da rede tenha decaído ao longo dos anos, manteve-se alto (entre 0,9 e 1). Os valores da modularidade, ao contrário, cresceram no sentido inverso (de 0,9 para 1), mostrando que a rede RBIE tem caminhado no sentido da formação de ilhas conectadas internamente. Confirmando esta tendência, a formação de grupos pequenos, onde autores novos chegam em grupos, já observada quando a rede foi analisada ano a ano, de modo estático.

O grau médio da rede se mantém estável ao longo dos anos não ultrapassando o valor 3 , levando a crer que seja então uma boa média de pessoas para a construção de trabalhos de qualidade, como aqueles já publicados na RBIE.

Ainda na Tabela 8, observando-se a evolução do diâmetro da rede RBIE comparada com o crescimento do número de vértices, constata-se que, ao longo dos anos, não houve retrações, pelo contrário, a rede tendeu a alargar, mostrando que novos autores estão se conectando a autores não tão centrais, àqueles que estão "nas pontas" da rede, ou seja, àqueles que possuem maiores distâncias dos demais, e consequentemente com centralidade global baixa. Indicando que não há uma tendência conhecida como preferential attachment [25], onde novos autores estariam escrevendo artigos com pessoas que já estivessem na rede e que fossem destaque na centralidade de grau, como se os "famosos" atraíssem mais pessoas que os que não possuem tantos laços. De fato, não parece ser o caso da rede RBIE. 


\begin{tabular}{|c|c|c|c|c|c|c|c|c|}
\hline $\begin{array}{l}n \\
0 \\
\text { 出 }\end{array}$ & $\begin{array}{c}n \\
0 \\
0 \\
-7 \\
+4 \\
y \\
0 \\
>\end{array}$ & 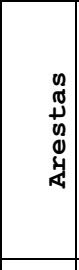 & 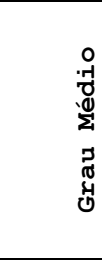 & 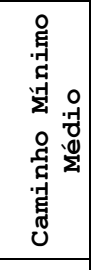 & 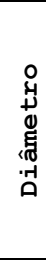 & 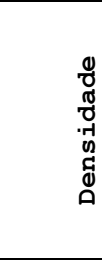 & $\begin{array}{l}0 \\
0 \\
0 \\
0 \\
-7 \\
-7 \\
\pi \\
-5 \\
0 \\
0 \\
0\end{array}$ & 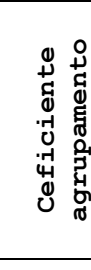 \\
\hline $97-98$ & 50 & 59 & 2,36 & 1,09 & 2 & 0,048 & 0,890 & 0,98 \\
\hline 97-99 & 81 & 97 & 2,39 & 1,12 & 2 & 0,030 & 0,928 & 0,96 \\
\hline $97-00$ & 101 & 117 & 2,31 & 1,14 & 2 & 0,023 & 0,940 & 0,95 \\
\hline 97-01 & 135 & 158 & 2,341 & 1,14 & 2 & 0,017 & 0,960 & 0,94 \\
\hline $97-02$ & 153 & 180 & 2,35 & 1,17 & 3 & 0,015 & 0,965 & 0,92 \\
\hline $97-03$ & 175 & 206 & 2,35 & 1,19 & 3 & 0,014 &, 968 & 0,92 \\
\hline $97-04$ & 199 & 233 & 2,34 & 1,2 & 3 & 0,012 & 0,972 & 0,92 \\
\hline $97-05$ & 229 & 275 & 2,4 & 1,29 & 3 & 0,010 & 0,970 & 0,91 \\
\hline $97-06$ & 262 & 344 & 2,62 & 1,46 & 4 & 0,010 & 0,960 & 0,91 \\
\hline $97-07$ & 302 & 428 & 2,83 & 1,47 & 4 & 0,009 & 0,966 & 0,91 \\
\hline $97-08$ & 343 & 485 & 2,83 & 1,52 & 4 & 0,008 & 0,970 & 0,91 \\
\hline 97-09 & 369 & 522 & 2,82 & 1,58 & 5 & 0,008 & 0,970 & 0,9 \\
\hline $97-10$ & 402 & 570 & 2,8 & 1,62 & 5 & 0,007 & 0,973 & 0,9 \\
\hline $97-11$ & 444 & 625 & 2,8 & 2,1 & 7 & 0,006 & 0,974 & 0,9 \\
\hline $97-12$ & 503 & 716 & 2,8 & 2,24 & 7 & 0,006 & 0,974 & 0,9 \\
\hline $97-13$ & 583 & 874 & 2,99 & 2,13 & 7 & 0,005 & 0,971 & 0,9 \\
\hline
\end{tabular}

Diante do comportamento da rede RBIE, estudado de modo dinâmico, observa-se que a mesma encontra-se em crescimento constante quanto ao número de participantes, que, em sua maioria, chegam em grupos formando ilhas internamente conectadas, resultando numa rede esparsa e modularizada.

É importante que sejam identificadas quais são as conexões entre estas ilhas. Talvez seja através destes autores o caminho para o sucesso no incentivo às trocas entre autores que ainda não tenham um laço entre si. Levanta a hipótese da possibilidade de estes autores serem as pontes entre diferentes grupos e/ou instituições. Neste caso, devem ser identificados quais são os autores que possuem alto grau de intermediação na rede.

\subsection{2 - Medidas relativas aos autores}

As medidas de centralidade global e o coeficiente de agrupamento foram calculados para os autores na rede construída com o acúmulo de dados a cada ano. No entanto, para o grau de agrupamento, viu-se um grande número destes autores atingindo grau máximo, no valor de 1. Para o valor da centralidade global, o inverso, muitos autores com valores mínimos. Sendo assim, tais análises não foram proveitosas para destacar autores através destas medidas.

Continuando a análise das medidas relativas aos autores a Tabela 9 traz os resultados para os aqueles com os dez maiores graus de centralidade na sua parte superior, e na parte inferior, aqueles dez autores que mais se destacaram no grau de intermediação, dispostos desta maneira para facilitar uma comparação entre estes resultados.

Ainda na Tabela 9, observando a rede como um emaranhado de relações que se formaram ao longo dos 17 anos estudados, percebe-se que os autores que se destacaram por terem estabelecido parcerias com diferentes outros autores são os mesmos desde 1997, primeiro ano estudado, até 2005 (destacados em cinza claro). Do ano de 2006 até o ano de 2010 pode-se ver que há alguma renovação com relação aos autores que se destacam no grau de centralidade. Desde 2010 até 2013 é possível acompanhar um grupo de 7 autores que permanecem em sua maioria até 2013, são eles: 152,171 , 172, 173, 272, 273, 274 (destacados na cor cinza médio). A partir do ano de 2007, começam a aparecer outros autores que, por terem formado novas parcerias, alcançam os maiores graus e permanecem em destaque até 2013 (cinza escuro). Ainda, dentre os dez autores em destaque para cada ano, é possível perceber que o autor 152 aparece constantemente nos últimos 8 anos estudados mantendo, no entanto, a diversidade de parcerias com 12 outros autores por todo esse tempo. Por outro lado, o autor 80 se destaca entre os dez pela primeira vez em 2007, com 9 diferentes parcerias formadas e, desde então, vem acrescentando constantemente novos autores aos seus laços de coautoria, chegando ao grau 19 em 2013.

Comparando a evolução do grau médio da rede, estável ao longo dos anos e a evolução do diâmetro da rede, sempre crescente e da análise dos graus médios atingidos pelos autores que se destacaram, a rede RBIE não tem tido a tendência de possuir pontos de concentração de conexões. Apesar de serem pesquisadores que têm influenciado as pesquisas na área, não parece que estes autores estejam concentrando parcerias em detrimento dos demais. Como foi observado, o maior grau foi atingido pelo autor 80 , com 19 conexões diferentes, dentre os 625 autores que já publicaram na Revista. 


\begin{tabular}{|c|c|c|c|c|c|c|c|c|c|c|c|c|c|c|c|c|c|c|c|c|c|c|c|c|c|c|c|c|c|c|c|}
\hline \multicolumn{2}{|c|}{$97-98$} & \multicolumn{2}{|c|}{ 97-99 } & \multicolumn{2}{|c|}{$97-00$} & \multicolumn{2}{|c|}{$97-01$} & \multicolumn{2}{|c|}{ 97-02 } & \multicolumn{2}{|c|}{ 97-03 } & \multicolumn{2}{|c|}{$97-04$} & \multicolumn{2}{|c|}{ 97-05 } & \multicolumn{2}{|c|}{$97-06$} & \multicolumn{2}{|c|}{ 97-07 } & \multicolumn{2}{|c|}{ 97-08 } & \multicolumn{2}{|c|}{ 97-09 } & \multicolumn{2}{|c|}{$97-10$} & \multicolumn{2}{|c|}{ 97-11 } & \multicolumn{2}{|c|}{$97-12$} & \multicolumn{2}{|c|}{$97-13$} \\
\hline id & grau & id & grau & id & grau & id & grau & id & grau & id & grau & id & grau & id & grau & id & grau & id & grau & id & grau & id & grau & id & grau & id & grau & id & grau & id & grau \\
\hline 56 & 5 & 56 & 5 & 56 & 5 & 56 & 5 & 56 & 5 & 56 & 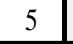 & 56 & 5 & 36 & 6 & 152 & 12 & 152 & 12 & 152 & 12 & 80 & 14 & 80 & 14 & 80 & 14 & 80 & 16 & 80 & 19 \\
\hline 12 & 4 & 90 & 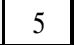 & 90 & 5 & 90 & 5 & 90 & 5 & 90 & 5 & 90 & 5 & 101 & 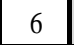 & 172 & 8 & 80 & 9 & 00 & 11 & 152 & 12 & 152 & 12 & 152 & 12 & 152 & 12 & 367 & 16 \\
\hline 13 & 4 & 91 & 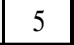 & 91 & 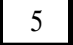 & 91 & $\pi$ & 91 & 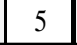 & 91 & 5 & 91 & 5 & 56 & 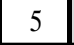 & 171 & 1 & 46 & 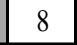 & 278 & T- & 278 & 9 & 114 & 11 & 114 & 11 & 114 & 11 & 309 & 13 \\
\hline 14 & 4 & 92 & 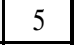 & 92 & 5 & 92 & 5 & 92 & 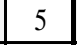 & 92 & 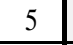 & 92 & 5 & 90 & 5 & 173 & 7 & 172 & - & 46 & 8 & 46 & 8 & \begin{tabular}{|l|} 
\\
\end{tabular} & 9 & 312 & 10 & 309 & 11 & 152 & 12 \\
\hline 15 & 4 & 93 & 5 & 93 & 5 & 93 & 5 & 93 & 5 & 93 & 5 & 93 & 5 & 91 & 5 & 272 & 7 & 171 & 7 & 172 & 8 & 101 & 8 & \begin{tabular}{|l|}
367 \\
\end{tabular} & 9 & 278 & 0 & 312 & 11 & 114 & 11 \\
\hline 16 & 4 & 94 & 5 & 94 & 5 & 94 & 5 & 94 & 5 & 94 & 5 & 94 & 5 & 92 & 5 & 273 & 7 & 173 & 7 & 171 & 7 & 172 & 8 & 46 & 8 & 309 & 9 & 56 & 9 & 279 & 11 \\
\hline 50 & 4 & 95 & 5 & 95 & 5 & 95 & 5 & 95 & 5 & 95 & 5 & 95 & 5 & 93 & 5 & 274 & 7 & 249 & 7 & 173 & 7 & 171 & 7 & 101 & 8 & 367 & 9 & 278 & 9 & 312 & 11 \\
\hline 51 & 4 & 12 & 4 & 12 & 4 & 12 & 4 & 12 & 4 & 187 & 5 & 187 & 5 & 94 & 5 & 275 & 7 & 272 & 7 & 249 & 7 & 173 & 7 & 172 & 8 & 46 & 8 & 313 & 9 & 172 & 10 \\
\hline 52 & 4 & 13 & 4 & 13 & 4 & 13 & 4 & 13 & 4 & 12 & 4 & 12 & 4 & 95 & 5 & 276 & 7 & 273 & 7 & 272 & 7 & 249 & 7 & 171 & 7 & 101 & 8 & 367 & 9 & 420 & 10 \\
\hline 53 & 4 & 14 & 4 & 14 & 4 & 14 & 4 & 14 & 4 & 13 & 4 & 13 & 4 & 142 & 5 & 277 & 7 & 274 & 7 & 273 & 7 & 272 & 7 & 173 & 7 & 172 & 8 & 46 & 8 & 56 & 9 \\
\hline \multicolumn{2}{|c|}{$\begin{array}{c}\text { id/interme } \\
\text { diaçãao }\end{array}$} & \multicolumn{2}{|c|}{$\begin{array}{c}\text { id/interme } \\
\text { diação }\end{array}$} & \multicolumn{2}{|c|}{$\begin{array}{c}\text { id/interme } \\
\text { diaçãa }\end{array}$} & \multicolumn{2}{|c|}{$\begin{array}{c}\text { id/interme } \\
\text { diação }\end{array}$} & \multicolumn{2}{|c|}{$\begin{array}{c}\text { id/interme } \\
\text { diação }\end{array}$} & \multicolumn{2}{|c|}{$\begin{array}{c}\text { id/interme } \\
\text { diação }\end{array}$} & $\begin{array}{r}\text { id/int } \\
\text { dia }\end{array}$ & & dia & & $\begin{array}{r}\text { id/int } \\
\text { dia }\end{array}$ & ce & $\operatorname{dia}$ & & dia & & $\begin{array}{r}\text { id/int } \\
\text { dia }\end{array}$ & & $\begin{array}{r}\text { id/inte } \\
\text { diaç }\end{array}$ & & dias & & $\begin{array}{r}\text { id/int } \\
\text { dia }\end{array}$ & & dia & \\
\hline 56 & 6 & 56 & 6 & 56 & 6 & $56:$ & 6 & 56 & 6 & 56 & 6 & 566 & 6 & 36 & 12 & 152 & 71 & 152 & 71 & 152 & 71 & 80 & 98 & 80 & 98 & 268 & 179 & 114 & 239 & 114 & 251 \\
\hline- & 0 & 33 & 5 & 33 & 5 & 33 & 5 & 33 & 5 & 187 & 6 & 87 & 6 & 187 & 10 & 172 & 21 & 80 & 37 & 80 & 59 & 152 & 71 & 114 & 71 & 266 & 133 & 268 & 209 & 309 & 231 \\
\hline- & 0 & 28 & 2 & 28 & 5 & $28:$ & 5 & 28 & 5 & 33 & 5 & 187 & 6 & 189 & 10 & 36 & 12 & 12 & 21 & 189 & 25 & 28 & 29 & 152 & 71 & 30 & 130 & 423 & 196 & 423 & 210 \\
\hline- & 0 & - & 0 & 69 & 2 & 89 & 3 & 77 & 4 & 28 & 5 & 33 & 5 & 100 & 7 & 76 & 12 & 28 & 19 & 8 & 23 & 189 & 25 & 367 & 30 & 68 & 109 & 309 & 182 & 80 & 207 \\
\hline- & 0 & - & 0 & 30 & 1 & 69 & 2 & 76 & 3 & 47 & 4 & 28 & 5 & 101 & 7 & 163 & 12 & 36 & 12 & 227 & 21 & 101 & 21 & 28 & 29 & 801 & 98 & 80 & 147 & 68 & 145 \\
\hline- & 0 & - & 0 & 3 & 0 & 77 & 2 & 89 & 3 & 100 & 4 & 36 & 4 & 56 & 6 & 77 & 10 & 46 & 12 & 172 & 21 & 227 & 21 & 189 & 25 & 163 & 88 & 266 & 147 & 36 & 126 \\
\hline- & 0 & - & 0 & 4 & 0 & 100 & 2 & 152 & 3 & \begin{tabular}{|l|}
76 \\
\end{tabular} & 3 & 77 & 4 & 87 & 6 & 187 & 10 & 76 & 12 & 187 & 16 & 172 & 21 & 101 & 22 & 69 & 71 & 56. & 121 & 268 & 120 \\
\hline- & 0 & - & 0 & 5 & 0 & 30 & 1 & 69 & 2 & 89 & 3 & 100 & 4 & 142 & 6 & 189 & 10 & 163 & 12 & 278 & 14 & 163 & 16 & 227 & 21 & 11 & 71 & 68 & 119 & 358 & 104 \\
\hline- & 0 & - & 0 & 6 & 0 & 85 & 1 & 100 & 2 & 134 & 3 & 76 & 3 & 33 & 5 & 33 & 8 & 249 & 12 & 36 & 12 & 187 & 16 & 172 & 21 & 152 & 71 & 358 & 100 & 163 & 100 \\
\hline- & 0 & - & 0 & 7 & 0 & 86 & 1 & 114 & 2 & 152 & 3 & 89 & 3 & 28 & 5 & 171 & 7 & 77 & 10 & 46 & 12 & 76 & 15 & 163 & 16 & 76 & 69 & 163 & 96 & 152 & 85 \\
\hline
\end{tabular}

Tabela 9 - Relação dos identificadores dos dez autores em destaque pela centralidade de grau e os dez autores em destaque pelo grau de intermediação relativa aos dados acumulados desde 1997 a 2013. 


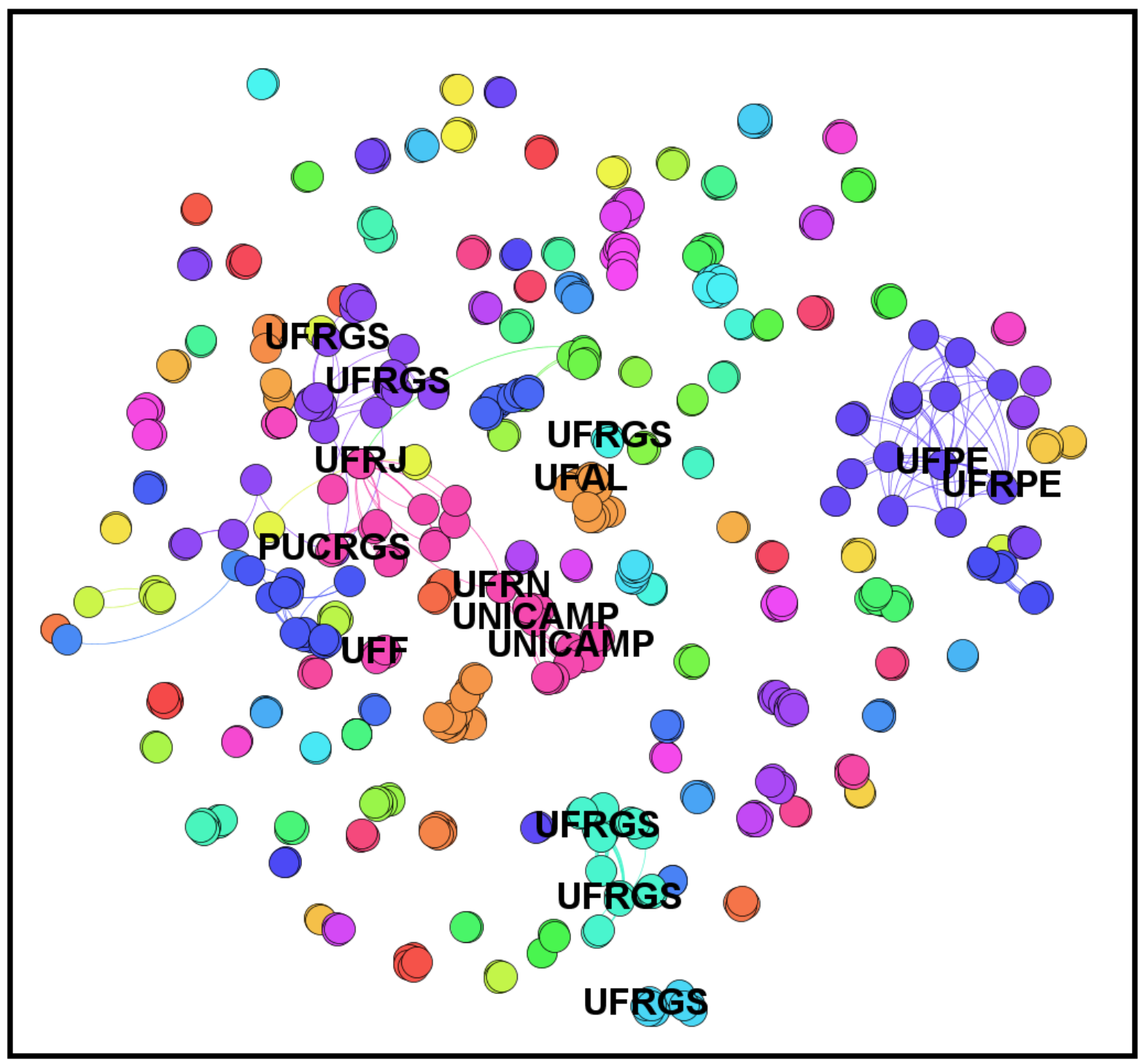

Figura 6 - Representação das comunidades de autores e universidades respectivas àqueles que se destacaram em termos de centralidade de grau e grau de intermediação na rede RBIE. Os autores são representados por círculos. Uma mesma comunidade é representada por círculos próximos e de mesma cor. 
Comparando os autores em destaque para o grau de centralidade com aqueles que ocuparam os dez maiores índices para o grau de intermediação, acontece a mesma tendência, aqueles autores que ocupavam uma posição de intermediação, vistos a partir de 1997, se mantêm, em sua maioria, até o ano de 2005 , quando a partir daí outros autores começam a ocupar as dez primeiras posições de intermediação entre os demais autores. Pode-se observar que, embora não sejam os mesmos autores em destaque nas duas medidas feitas, há alguns que acumulam as duas responsabilidades: estão conectados com várias pessoas diferentes e estão no caminho entre várias outras. É o caso do autor 56 entre os anos 1997 e 2005, em 2012 e 2013. A partir de 2006, um grupo maior de autores fizeram estes dois papéis, são eles: $80,114,152,309$, sugerindo que estes sejam os autores influentes em suas comunidades.

Em seções anteriores a esta, constatou-se que a rede RBIE é composta por comunidades internamente conectadas, porém desconexas umas das outras. A Figura 6 mostra estas comunidades, e ressalta as universidades de origem respectivas aos autores que se destacam pela centralidade de grau e grau de intermediação. Na figura, os autores são representados por círculos. Autores de uma mesma comunidade, ou seja, onde exista um caminho entre eles, são representados por círculos próximos e de mesma cor.

Uma análise da Figura 6 reporta que 7 dos 15 autores em destaque são oriundos de universidades do sul do Brasil, 4 do Nordeste e 4 da região Sudeste. Ressaltando, desta maneira, que a região que mais colabora e faz a intermediação de relacionamentos é a região Sul do país.

Estes fatos, a respeito das comunidades de autores, ajudam a revelar que a rede RBIE, para que caminhe no sentido de facilitar a existência de uma rede nacional composta por redes regionais de relacionamentos, necessita estimular o fortalecimento dos laços entre as universidades e respectivos autores que já fazem parte da rede, tornando-a mais densa.

Surge então a questão: os autores identificados nesta pesquisa são os mesmos que se destacam na área de Informática na Educação no Brasil? Para haver um esclarecimento quanto a isso, verificaram-se os nomes e respectivas instituições das quais são oriundos. Tal relação foi submetida a um especialista da área para o auxílio nesta avaliação, e de fato, os autores identificados neste trabalho são conhecidos e possuem o respeito da comunidade como um todo. Estes representantes e suas respectivas instituições de atuação possuem grande relevância e devem receber estímulo para realização de parcerias a fim de conectar comunidades, até então, com trabalhos independentes umas das outras.

\section{6 - Conclusões e Trabalhos Futuros}

Este trabalho analisou os dados relativos às publicações na comunidade de Informática na Educação representada pela RBIE sob a luz da Análise de Redes Sociais, com os quais a estrutura de uma rede de coautorias foi levantada e estudada. Composta por autores representados por vértices e a escrita de um artigo em comum uma aresta entre tais vértices, um grafo foi construído.

A rede resultante foi observada sob duas óticas, a primeira, chamada de estática, onde os dados relativos a cada ano de publicação da Revista foram tomados independentemente daqueles que diziam respeito a anos anteriores. Na segunda abordagem, chamada de dinâmica, a rede foi observada através da evolução ano a ano da chegada de novos autores e formação de novas arestas, acumulando estes dados aos que já estavam computados referentes aos anos anteriores. Em ambas as abordagens métricas clássicas da Teoria dos Grafos foram aplicadas, avaliando-se a rede como um todo e também numa análise da importância de cada vértice.

O número de artigos publicados e de autores entrando na rede a cada ano tem crescido constantemente desde o ano de 2009. No entanto, a taxa de crescimento do número de autores é muito maior que a de artigos publicados. Por um lado, entende-se a quantidade de artigos como sendo o resultado de uma limitação imposta pela própria Revista. Por outro lado, confirma-se o fato de que a colaboração na escrita e publicação de artigos tem aumentado.

O coeficiente de agrupamento médio da rede, embora tenha decaído ao longo dos anos se manteve com um valor alto. Quanto à modularidade da rede, também cresceu mostrando que a mesma tem caminhado no sentido da formação de ilhas conectadas internamente e desconectadas entre si. Esta tendência foi observada tanto na análise estática quanto na análise dinâmica.

$\mathrm{Na}$ análise da evolução do grau médio da rede, viuse que se manteve estável ao longo dos anos, em torno de 3, em ambas abordagens. Sugerindo ser uma quantidade média razoável de pessoas para a construção de trabalhos de qualidade, como aqueles que já têm sido publicados na RBIE. Trata-se de uma comunidade que tende a escrever e publicar seus trabalhos em coautoria..

A evolução do diâmetro da rede RBIE, observada de modo dinâmico, comparada com o constante crescimento do número de vértices, mostra que a rede vem se alargando, e que possivelmente novos autores estão se conectando a autores não tão centrais, àqueles que estão "nas pontas" da rede, ou seja àqueles que possuem maiores distâncias dos demais. Indicando que não há uma tendência de preferential attachment [25].

Ainda sobre o crescimento no número de autores na rede RBIE pode-se imaginar que se trata de uma comunidade ainda 
em fase de amadurecimento e expansão com espaço para novos laços de trabalhos. Supôs-se também que, devido a intensificação do rigor na avaliação dos Programas de Pesquisa em termos de produção de artigos, realizada periodicamente pela CAPES, somada ao índice Qualis "B" atribuído à Revista, a comunidade de Informática na Educação no Brasil esteja mais empenhada em publicar artigos na mesma.

Observou-se que este crescimento no número de participantes, em sua maioria, caracteriza-se pela chegada de grupos, formando ilhas, internamente conectadas, resultando numa rede esparsa e modularizada. Sendo assim, através de comparações feitas sobre os resultados das medições do grau de intermediação e centralidade de grau dos vértices, destacaram-se os autores e suas respectivas instituições que possivelmente fazem ou têm potencial para fazer o papel de ponte entre estas ilhas.

Identificadas as instituições sugere-se que algumas disciplinas oferecidas em seus Programas de Pós Graduação pudessem ser cursadas por alunos de universidades distintas, talvez numa modalidade a distância, incentivando assim a formação de parcerias e as trocas entre as comunidades já existentes.

Ao contrário de outros trabalhos [8], apesar de a rede RBIE apresentar um coeficiente de agrupamento médio alto e caminho mínimo curto, a maior comunidade interna encontrada não tem um tamanho adequado para se afirmar que o fenômeno small world acontece.

Através do presente trabalho, a RBIE, representada pela comunidade que escreve suas publicações, passa a ter ciência de como esta comunidade está estruturada em termos de laços entre indivíduos e entre comunidades menores que a compõem. Sabendo que se trata de uma rede formada por ilhas, com espaço para novas conexões, e de posse da identificação dos autores que possivelmente são chave para estas conexões se efetivarem, a Revista se torna um campo propício para a implementação de políticas de incentivo para não somente o aumento da produtividade em termos de número de artigos de qualidade publicados, mas também no sentido da formação de parcerias estratégicas para o sucesso nas trocas de produtos e conhecimento.

Como mencionado na seção de trabalhos correlatos, outras abordagens também poderiam servir como ferramenta de análise da mesma base de dados utilizada no presente trabalho, tais como a formação de cliques, ou a análise semântica sobre os títulos utilizados ao longo do tempo. Outro estudo pertinente seria verificar se a rede apresenta o efeito "cauda longa" analisando a distribuição dos graus e o número de artigos publicados referentes a cada autor.

\section{Agradecimentos}

Agradecemos aos responsáveis pela RBIE pelos dados disponibilizados e aos professores Herli Joaquim Menezes, Juliana Valério, Daniel Sadoc e Claudia L. R. Motta pelo auxilio no processo de aquisição e tratamento dos dados desta pesquisa.

\section{Glossário}

Caminho Mínimo ou Distância Mínima: menor número de arestas entre dois vértices na rede.

Caminho Mínimo Médio da Rede: média dos caminhos mínimos relativos a cada vértice da rede.

Centralidade: indica a importância do vértice/autor.

Coeficiente de Agrupamento: a probabilidade de que dois vizinhos de um vértice serão vizinhos entre si.

Densidade da Rede: descreve o nível de ligação entre os vértices da rede. Numa rede de coautorias expressa a relação entre o número de conexões existentes entre os autores e o número máximo total de conexões que poderiam ser constituídas. Ao contrario de uma rede esparsa, numa rede densa a maioria dos laços já foram formados.

Diâmetro da Rede: maior caminho mínimo entre dois vértices da rede.

Distância: quantidade de arestas que existem entre dois vértices.

Grafo: composto por vértices e arestas. Cada vértice é um autor. Uma aresta existe entre dois autores que escreveram um artigo em coautoria.

Grau de Centralidade de um vértice/autor: número de arestas conectadas diretamente a ele/número de autores diferentes com os quais um determinado autor escreveu um artigo.

Grau de Intermediação: quanto um vértice está no caminho entre os outros vértices numa rede. Quanto maior for o valor deste grau, significa que este vértice é uma passagem obrigatória entre as menores distâncias entre os vértices de um grafo.

Modularidade da Rede: quantifica a qualidade da divisão da rede em módulos ou comunidades.

\section{Referências}

[1] V. V. Odakura e C. A. Barvinski. SBIE, WIE e RBIE: publicações da comunidade brasileira de Informática na Educação. In Anais do Workshop de Desafios da Computação Aplicada à Educação, páginas 218-226, 2012.

[2] M.F. Elia. Dez Anos da RBIE: Retrospectiva e Desafios. Revista Brasileira de Informática na 
Educação, 15.3, 2007.

[3] I.S. Fadigas, M.V. Cunha, M.G. Rosa, H.B.B. Pereira. Análise de Redes de Coautoria por Meio de Redes Semânticas Uniformes. BraSNAM Workshop Brasileiro de Analise de Redes Sociais, Anais do XXXIII, Congresso da Sociedade Brasileira de Computação, 2013.

[4] J.L.Moreno. Who Shall Survive? Beacon House, Beacon, NY, 1934.

[5] M. E. J. Newman. Networks: An Introduction. Oxford University Press, 2010.

[6] C.Morel,; S.J. Serruya; G.P. Penna; R. Guimarães. Co-authorship Network Analysis: A Powerful Tool for Strategic Planning of Research, Development and Capacity Building Programs on Neglected Diseases, v. 3, p. e501, 2009.

[7] M. G. Rosa, I. S. Fadigas, M. T. T. Andrade e H. B. B. Pereira. Abordagem de Redes por Cliques: Aplicação a Redes de Coautoria. BraSNAM Workshop Brasileiro de Analise de Redes Sociais, Anais do XXXII Congresso da Sociedade Brasileira de Computação, volume 1, 2012.

[8] W. Mendes-da-Silva, L.M. Onusic, E.M. Giglio, Rede de Pesquisadores de Finanças no Brasil: Um Mundo Pequeno Feito por Poucos. RAC Revista de Administração Contemporânea, Rio de Janeiro, Volume 17, número 6, artigo 6, páginas:739-763, 2013.

M. E. J. Newman. Coauthorship Networks and Patterns of Scientific Collaboration. Proceedings of the National Academy of Sciences of the United States of America 101.Suppl 1, páginas: 5200-5205. 2004

[10] M.V. Cunha, M.G. Rosa, I.S. Fadigas, J.G.V. Miranda e H.B.B. Pereira. Redes de Títulos de Artigos Científicos Variáveis no Tempo. BraSNAM - Workshop Brasileiro de Análise de Redes Sociais, Anais do XXXIII Congresso da Sociedade Brasileira de Computação, 2013.

[11] L. A. Digiampietri, J.P. Mena-Chalco, G.S.Silva, L. B. Oliveira, A. P. Malheiros e D. Meira. Dinâmica das Relações de Coautoria nos Programas de Pós Graduação em Computação no Brasil. BraSNAM - Workshop Brasileiro de Analise de Redes Sociais, Anais do XXXII Congresso da Sociedade Brasileira de Computação, 2012.

[12] M. E. J. Newman. The Structure of Scientific Collaboration Networks . Proceedings of the National Academy of Sciences 98.2, 404-409, 2001 .
[13] F. Amblard, A. Casteigts, P. Flocchini, W. Quattrociocchi, N. Santoro. On the Temporal Analysis of Scientific Network Evolution; International Conference on Computational Aspects of Social Networks (CASoN), 169-174, 2011.

[14] A. Flocchini, A. Quattrociocchi e N. Santoro. Time-Varying Graphs and Dynamic Networks. In Frey, H., Li, X., and Ruhrup,S., editors, ADHOC-NOW, volume 6811, Lecture Notes in Computer Science, 346-359. Springer. 2011.

[15] S.Wasserman e K. Faust, Social Networks Analysis: Methods and Applications. Cambridge: Cambridge University Press, 1994

[16] J. Scott, Social Network Analysis - A Handbook, Sage Publication, 2001

[17] G.Sabidussi. The centrality index of a graph. Psychometrika, 31(4), 581-603. 1966.

[18] U. Brandes, A Faster Algorithm for Betweenness Centrality, in Journal of Mathematical Sociology 25(2):163-177, (2001)

[19] W. S. McCulloch and W. Pitts. A logical calculus of the ideas immanent in nervous activity. The bulletin of mathematical biophysics 5.4 (1943): 115-133.

[20] M. E. J. Newman. Clustering and Preferential Attachment in Growing Networks, Physical Review E 64, 025102, 2001

Gephi Graph Visualization and Manipulation Software GNU General Public License version 0.8.2. https://gephi.org/

[22] D. J Watts, and S. H. Strogatz. Collective dynamics of small-world networks. Nature,393.6684 (1998): 440-442.

[23] M. E. J. Newman. The structure and Function of Complex Networks. SIAM review 45.2, páginas: 167-256, 2003.

[24] J. Travers, and S. Milgram. An experimental study of the small world problem. Sociometry (1969): 425-443.

[25] A. L. Barabási, H. Jeong, Z. Néda, E. Ravasz, A. Schubert e T. Vicsek. Evolution of The Social Network of Scientific Collaborations. Physica A: Statistical Mechanics and its Applications, 311(3), 590-614, 2002

[26] T. Kuhn. A Estrutura das Revoluções Científicas ( $2^{\mathrm{a}}$ edição). São Paulo, Perspectiva, 1978.

[27] V. Ströele, R. Silva, M. F. Souza, C. E. R. de Mello, J. M. Souza, G. Zimbrao, and J. Oliveira. Identifying Workgroups in Brazilian Scientific Social Networks. Journal of Universal Computer 
Science 17, no. 14 (2011): 1951-1970.

[28] M. A.,Tamanini, P. Braga , T. G. Carneiro, N. M. Ribeiro , A. Moret, H. M. B., Pereira (2014) Contextualized Analysis of Social Networks: Collaboration in Scientific Communities.Social Networking,3,71-79. doi:10.4236/sn.2014.32009

[29] V. Ströele, G. Zimbrão, and J. M. Souza. Group and link analysis of multi-relational scientific social networks. Journal of Systems and Software86.7 (2013): 1819-1830.

[30] Ata da Reunião da Comissão Especial de Informática na Educação. Acessada em 18 de novembrode2014.http://www.sbc.org.br/index.ph $\mathrm{p}$ ?option $=\mathrm{com}$ jdownloads\&Itemid $=195 \&$ task $=\mathrm{f}$ inish\&cid $=30 \&$ catid $=67$ 